\title{
Effect of Soil-Pile-Structure Interaction on Seismic Design of Tall and Massive Buildings Through Case Studies
}

\section{Sassan Mohasseb, et al. [full author details at the end of the article]}

Accepted: 1 July 2019 / Published online: 6 August 2019

(C) The Author(s) 2019

\begin{abstract}
In this study, the effects of Soil-Pile-Structure Interaction (SPSI) forces on the seismic response of two tall and massive building projects were investigated. The first case study is an emergency hospital building located in south of Switzerland which is an existing reinforced concrete construction with concrete columns. Due to the importance of the building and its potential danger in failure cases of the load-bearing structure, seismic analysis was first carried out by using a 3D finite element model for the entire structure and a new FORTRAN program based on the enhanced cone model for the soil under the structure. The implementation of simulation was conducted in two different conditions, namely fixed-base behavior and soil-structure interaction, which are considered. Based on the results obtained by using the cone frustum approach, the period of vibration in the case of concentrated piles with the correction factor for pile-group action, exhibiting the value of $(1.2 \mathrm{~s})$, is increased up to $42 \%$ compared with the case of fixed-base $(0.7 \mathrm{~s})$. In the second phase, the dynamic responses of the Green Building at the MIT campus in Cambridge during three ground motions were studied through both approaches. It has shown that the first period of vibration in the case of the MIT Science building increased by about $11 \%$ (from 1.37 to $1.53 \mathrm{~s}$ ) with respect to the SPSI effect. Besides, a comparison was made between the structural responses of the obtained cone method and 3D finite element simulation in ABAQUS which indicated that these results were in good agreement with the direct results. It was concluded that the enhanced cone model as a convenient, fast, and rather accurate method can be applied for foundation vibration and dynamic soil-structure interaction analysis in practical engineering projects whenever possible.
\end{abstract}

Keywords Seismic analysis · Soil-Pile-Structure Interaction (SPSI) · Pile-group effect · Cone model $\cdot$ FEM method

\section{Introduction}

The Soil-Pile-Structure Interaction (SPSI) plays an important role in assessing the dynamic response to seismic ground motions or vibrations internally generated within the structural system. It is very important to note that the SPSI can alter the 
superstructure's performance by influencing the dynamic properties of the structure. A fundamental understanding of this complex phenomenon is essential for improvements of the structural design and construction practices, and, as a result, for reduction of loss of life and monetary damages caused by earthquakes. Extensive field testing and experimental investigations on different aspects of pile behavior have resulted in a number of empirical and approximate analytical methods for the pile-foundation design (Craig and Kurdila 2006; Han 2002; Guin and Banerjee 1998; Kaynia 1982; Dobry and Gazetas 1988; Chore et al. 2010). In addition, other studies have resulted in more rigorous schemes for pile analysis. The results of research from various studies also back up the point that dynamic impedance of foundation is affected by several geometric and material factors, such as foundation shape (i.e., disk, rectangular, strip), type of soil profile (i.e., deep uniform or multi-layer deposit, shallow stratum on rock), foundation embedment (i.e., surface foundation, embedded foundation, pile foundation), shear wave velocity and type of loading (static, dynamic) (Fan et al. 1991; Pitilakis et al. 2008).

Generally, three direct numerical approaches have so far been evolved for predicting the dynamic pile behavior. The first approach represents soil as an elastic continuum, the second represents the soil-pile system by a set of discrete masses, springs, and dashpots, and the third one uses either boundary element or finite element methods based on the actual soil properties (Kaynia and Kausel 1991; Massumi and Tabatabaiefar 2007).

The continuum model was considered to be a generalized Winkler model. The major contribution regarding this approach was carried out by Novak (1987), who introduced an approximate method based on the analytical solution of Baranov (1967). The soil was considered to be made of a set of independent infinitesimally thin horizontal layers in this model. Therefore, it automatically considered wave propagation in the horizontal direction. A set of equations for stiffness and damping ratio based on frequencyindependent parameters was provided for a single pile under vertical vibration. Thereafter, further progress on this model was made by Novak and Nogami (1977) and Dobry and Gazetas (1988). The reduction in soil stiffness and the increase in damping associated with strong shaking are sometimes modeled crudely in these analyses by making arbitrary reductions in shear moduli and arbitrary increases in viscous damping. Moreover, several researchers developed dynamic nonlinear finite element analysis in the time domain using the full 3-dimensional wave equations to investigate the seismic soil-structure interaction (Ismail et al. 2018), but it is not feasible for engineering practice at present because of the time needed for the computations. A rigorous finiteelement analysis of a pile foundation subjected to lateral loading was done by ÜlkerKaustell et al. (2010). These numerical methods have an advantage in that they can analyze the soil-pile system as a whole. Therefore, no separate analysis is required to calculate the dynamic interaction factors for pile-group analysis (Sadeghi Hokmabadi et al. 2012).

The major drawbacks of the analytical and numerical models in prior research studies were overcome with the introduction of the cone model which applies for shallow foundations on a half space. Afterwards, Wolf has rearranged and extended the concept of the cone model to cover a complete range of dynamic excitations and physical situations. The enhanced model was based on one-dimensional wave propagation in the cone segments with reflections and refractions at layer interfaces. Due to 
the simplification of the physical problem, the mathematics of the cone models can be solved rigorously (Pal and Baidya 2018; Jaya and Prasad 2004; Meek and Wolf 1994).

The present study investigates the effectiveness of applying the enhanced cone model to analyze the dynamic response of pile groups in two tall and massive building projects. For this purpose, a new computer program (FCONE) was developed based on the cone frustum model. This program utilizes the equivalent dynamic modeling concept in the analysis of soil dynamics and soil-pile-structure interaction.

\section{The Concept of Cone Model}

A simplified one-dimensional cone method was first introduced by Meek and Wolf (1994) to evaluate the dynamic response of a surface foundation on a half space (Wolf 1985). Linear behavior of the site is assumed; hence, the soil is assumed to remain linearly elastic with hysteretic material damping during dynamic excitation. Figure 1 shows the loaded disk on the surface of a homogeneous half space, modeled in the onedimensional strength-of-material approach as a truncated semi-infinite bar with a vertical axis (Wolf and Deeks 2004; Wolf 1994).

An enhanced method based on the cone frustum approach has been developed to model an embedded foundation that is an order of magnitude larger than the disk, such as a pile foundation in soil media. The soil region is divided into several segments by massless rigid disks covering the volume of foundation, as shown in Fig. 2. The disks will coincide with the interfaces of the half space. In addition, further disks are selected to adequately represent the dynamic behavior. After assemblage, the dynamic stiffness matrices of all the cone frustum segments are then calculated and subsequently assembled together with the underlying half space to form the dynamic stiffness matrix of the corresponding backbone cone. Applying a unit load at the disk and solving for

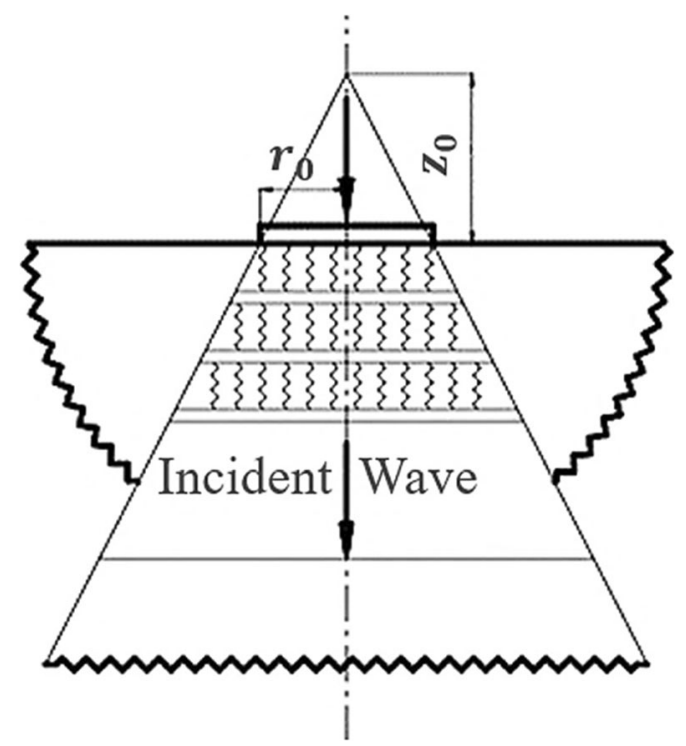

Fig. 1 Translational truncated semi-infinite cone model of a loaded disk on a half space 


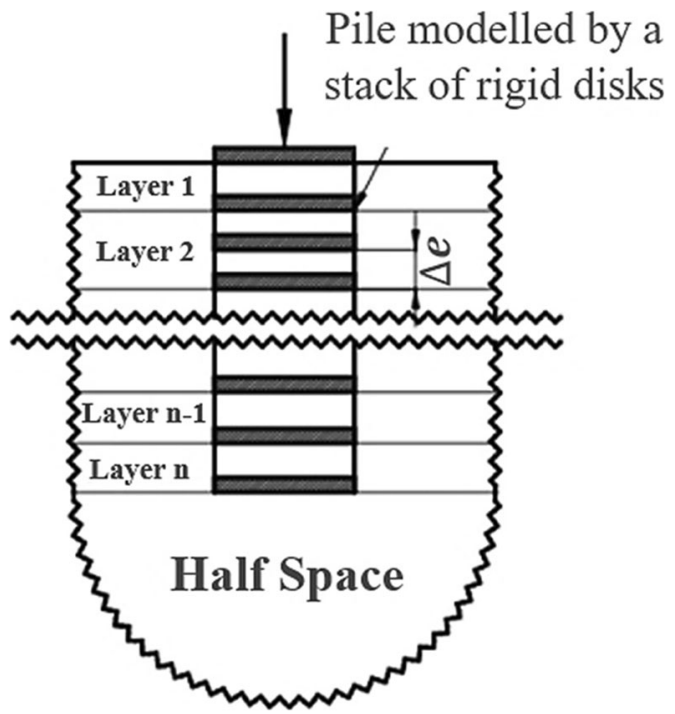

Fig. 2 Pile modeled by a stack of disks

the displacement amplitudes at all disks lead to a column in the flexibility matrix $[G(w)]$ of the free field condition. Thus, the force-displacement relationship is obtained as Eq. (1), where $\{u(w)\}$ is the displacement amplitudes and $\{P(w)\}$ is the force amplitudes:

$$
\{u(w)\}=[G(w)]\{P(w)\}
$$

This procedure is repeated for all disks to obtain all columns of the dynamic flexibility matrix $[G(w)]$. The dynamic stiffness of a single cone $S_{1}(w)$ modeling an incident wave induced by a disk load of radius $r_{0}$ on a half space is given by Eq. (2), where $K_{s}$ is the static translational stiffness coefficient of the cone modeling the incident wave, $c$ is the relevant wave velocity, $\omega$ is the load circular frequency, and $\rho$ is the soil density. The value of the aspect ratios of a particular cone is shown in Table 1 for each type of motion.

$$
S_{1}(w)=K_{s}\left(1+i \frac{w z_{0}}{c}\right) K_{s}=\frac{\rho c^{2} \pi r_{0}^{2}}{z_{0}}
$$

The dynamic stiffness matrix of the cone frustum segments is obtained by inverting the dynamic flexibility matrix $[S(w)]=\left[G^{-1}(w)\right]$, and, then, the forces acting on the top and bottom disks and their corresponding displacements are related as follows:

Table 1 Aspect ratios for different types of motion (Stewart et al. 1999a)

\begin{tabular}{lllll}
\hline Motion & Horizontal & Vertical & Rocking & Torsional \\
\hline Aspect ratio $\frac{z_{0}}{r_{0}}$ & $\frac{\pi}{8}(2-v)$ & $\frac{\pi}{4}(1-v)\left(\frac{c}{c_{s}}\right)^{2}$ & $\frac{9 \pi}{32}(1-v)\left(\frac{c}{c_{s}}\right)^{2}$ & $\frac{9 \pi}{32}$ \\
Poisson's ratio $v$ & All $v$ & $v \leq \frac{1}{3}, \frac{1}{3}<v \leq \frac{1}{2}$ & $v \leq \frac{1}{3}, \frac{1}{3}<v \leq \frac{1}{2}$ & All $v$ \\
\hline
\end{tabular}




$$
\{P(w)\}=\left[S^{f}(w)\right]\{u(w)\}
$$

It is well-known that the behavior of a pile in a compact group is quite different from that of a single pile because of pile-soil-pile interaction. These interaction effects depend mainly on pile spacing, frequency of excitation, and number of piles. These dynamic interactions are incorporated into the analysis by a factor which is defined as the ratio of fractional increase in displacement amplitude at receiver pile $u_{r} f(w)$ to the displacement amplitude at the loaded source pile $u_{s}(w)$. The dynamic normal-axial interaction factor $\alpha_{v}(w)$ can be obtained from Eq. (4), where $C_{s}$ is shear-wave velocity, $\zeta_{g}$ is hysteretic damping ratio, $\omega$ is frequency of excitation, $r_{0}$ is radius of the pile, and $d$ is distance between two piles. The following equation can also be written in polar coordinates $(\theta, r)$ to obtain good estimates for any arbitrary angle, where $u_{\theta} f(w)$ and $u_{\text {rad }} f(w)$ are tangential and radial displacement amplitudes at receiver pile, respectively:

$$
\begin{gathered}
\alpha_{v}(w)=\frac{u_{r}^{f}(w)}{u_{s}(w)}=\sqrt{\frac{r_{0}}{d}} e^{-\zeta_{g} w \frac{d}{c_{s}}} e^{-i w \frac{d}{c_{s}}} \\
u_{\theta}^{f}(w)=-\operatorname{Sin} \theta \cdot u_{r}^{f}\left(90^{\circ}, w\right) \\
u_{r a d}^{f}(w)=\operatorname{Cos} \theta \cdot u_{r}^{f}\left(0^{\circ}, w\right)
\end{gathered}
$$

When analyzing soil-structure interaction, two types of damping have to be taken into account, namely the geometric attenuation (radiation attenuation) that results from the distance of the excitation source to the object and the material damping due to the friction between the individual soil particles. The latter can be taken into account by substitution of $G$ and $G(1+2 i \zeta)$ and $E$ by $E(1+2 i \zeta)$, with $\zeta$ as the degree of attenuation of the soil. The material damping is independent of the excitation frequency (Meek and Wolf 1994; Wolf 1985).

When the distance between the piles is large (greater than about 20 diameters), the piles do not affect each other and the group stiffness and damping are simply the vector sums of the individual pile stiffness and damping. The dynamic stiffness matrix of the pile embedded in the half space can be obtained by replacing the properties of the soil between two consecutive disks with the mechanical properties of the pile section. This can be performed by adding the difference between the dynamic stiffness matrix of the pile and that of the corresponding soil cylinder $[\Delta S(w)]$, leading to:

$$
\begin{gathered}
S(w)=S^{f}(w)+\Delta S=S^{f}(w)+[\Delta K]-w^{2}[\Delta M] \\
\{P(w)\}=[S(w)]\{u(w)\}
\end{gathered}
$$

where $P(w)$ is force amplitude and $\Delta K$ and $\Delta M$ are the difference between stiffness matrices and mass matrices of the pile and soil cylinder, respectively. Equation (6) can be written as: 


$$
\left[\begin{array}{l}
P_{z} \\
P_{x} \\
p_{y} \\
m_{z} \\
m_{x} \\
m_{y}
\end{array}\right]=\left[\begin{array}{cccccc}
K_{\nu z}(w) & 0 & 0 & 0 & 0 & 0 \\
0 & K_{h x}(w) & 0 & 0 & 0 & K_{h x r y}(w) \\
0 & 0 & K_{h y}(w) & 0 & K_{\text {hyrx }}(w) & 0 \\
0 & 0 & 0 & K_{t z}(w) & 0 & 0 \\
0 & 0 & K_{h y r x}(w) & 0 & K_{r x}(w) & 0 \\
0 & K_{h x r y}(w) & 0 & 0 & 0 & K_{r y}(w)
\end{array}\right]\left[\begin{array}{l}
u_{z} \\
u_{x} \\
u_{y} \\
\varphi_{z} \\
\varphi_{x} \\
\varphi_{y}
\end{array}\right]
$$

where $v, h, r$, and $t$ denote vertical, horizontal, rocking, and torsional motions, respectively. It can be noted that coupling occurs between horizontal and rocking motions. Each coefficient of the impedance matrix is a complex function of the excitation frequency which can be expressed in the form of real and imaginary components. Furthermore, the dynamic stiffness coefficient obtained from the analysis is then decomposed into two parts:

$$
K_{i j}(w)=K_{s t}\left[k_{i j}+i a_{0} c_{i j}\right]
$$

In Eq. (8), $K_{s t}$ is the static stiffness, $i$ the imaginary unit, and $k_{i j}$ and $c_{i j}$, respectively called stiffness and damping coefficients, are dimensionless coefficients depending on the Poisson's coefficient of the soil and the frequency parameter.

$$
a_{0}=\frac{w\left(2 r_{0}\right)}{C_{s}}
$$

where $C_{s}=\sqrt{G / \rho}$ is the shear wave velocity in the soil. Finally, the total displacement of receiver pile $(i)$ due to lateral load of source pile $(j)$ can be written as:

$$
u_{i}(w)=\sum_{j=1}^{i-1} \alpha_{v}\left(d_{i j}, w\right) u_{j j}(w)+u_{i i}(w)+\sum_{j=i+1}^{n} \alpha_{v}\left(d_{i j}, w\right) u_{j j}(w), \quad(i=1, . ., n)(10)
$$

or

$u_{i}(w)=\frac{1}{S(w)}\left[\sum_{j=1}^{i-1} \alpha_{v}\left(d_{i j}, w\right) P_{j}(w)+P_{i}(w)+\sum_{j=i+1}^{n} \alpha_{v}\left(d_{i j}, w\right) P_{j}(w)\right], \quad(i=1, . ., n)$

In order to achieve a sufficient accuracy, the number of disks $n$ has to be selected so that the length $L$ of a pile element does not exceed about one tenth of the shortest wavelength propagating from the pile. Because the shear wave velocity is less than the dilatational wave velocity in the soil, the wavelength of shear waves is lesser than that of the longitudinal ones and the number of disks can be chosen as (Wolf and Deeks 2004; Wolf 1994):

$$
n \geq 1+\frac{5}{\pi}\left(\frac{L}{2 r_{0}}\right) a_{0}
$$




\section{Case Study 1: (an Emergency Hospital in South of Switzerland)}

The building is of a general rectangular shape with the overall dimensions of $73 \mathrm{~m}$ in the longitudinal direction, $25 \mathrm{~m}$ in the width direction, and a height of $35.6 \mathrm{~m}$. The building is a new reinforced concrete construction with concrete columns. The primary lateral load-carrying system consists of three reinforced cores and an integrated reinforced concrete exterior frame system. For the earthquake resistance evaluation, a special micro-zoning map and a response spectrum developed by Resonance Ltd. for Brig were used. The building is classified as a category III construction with an importance factor of 1.4. This is the highest class of building categories in Switzerland. The building was modeled in three dimensions (3D) and calculated for non-ductile behavior according to the SIA Standard 262 (2013 edition). The summary of the building characteristics and modeling assumptions is given in the succeeding texts.

\subsection{Modeling Assumptions}

\subsubsection{Longitudinal Direction}

The earthquake loads are carried by the three reinforced concrete cores and two shear walls together with the reinforced concrete framework. As the geometry of all floors is similar, continuous transfer of earthquake loads is guaranteed from the roof to the foundation. Additionally, due to the layout and stiffness differences, the mass center and the stiffness center of the building do not match resulting in torsional stresses due to lateral earthquake effects.

\subsubsection{Lateral (Short) Direction}

Three reinforced concrete core and two reinforced concrete frames transfer the horizontal equivalent loads corresponding to the earthquake effects from the higher levels through the lobby level to the basements of the building. There is a concern of soft story in the building. As a result, high shear stress concentrations occur in the building due to this irregularity.

Due to the stiffness differences, the resistance of the building in the short direction is lower than that in the longitudinal direction.

\subsection{Numerical Investigation}

The earthquake loads are determined according to the Swiss Code SIA 260-262; Merkblatt SIA 2018. The following material characteristics have been used: concrete: $E c=20,000 \mathrm{Mpa}$ (elastic modulus); $f^{\prime} c=19.2 \mathrm{Mpa}$ (compressive strength).

For the seismic structural analysis, the following four computer programs were used:

- ETABS, which is a well-known structural analysis and design software from CSI, Berkeley, USA.

- OpenSees or Open System for earthquake engineering Simulation. This is an earthquake simulation software based on the displacement-based structural 
analysis considering material non-linearities. The program is very suitable for assessing the behavior of buildings in seismic situations. The purpose of modeling with OpenSees is to perform a non-linear static pushover (NSP) analysis of the reinforced concrete system with concrete cores, shear walls, and the heavy concrete columns. The modeling is based on ASCE 41-13 (2014). Material non-linearities and hysteretic behavior are considered for the elements under normal forces, bending, and shear effects. For the calculations, both force-based and displacement-based methods have been used. For the displacement-based method, ASCE 41 procedures have been implemented in the calculation of target displacements.

- FCONE program was a new FORTRAN program developed at Smteam based on the enhanced cone model concept for soil modeling. This program utilizes the equivalent dynamic modeling concept in the analysis of soil dynamics and pilefoundation interaction.

- Abaqus/Cae was used to investigate the structure response according to seismic soilpile-structure interaction effect. The finite element simulation phase of the present study along with a description of boundary conditions, the meshing and analysis techniques, and the materials' constitutive laws is also presented in the subsequent texts.

\subsubsection{Pile Group Effect}

When piles are used as part of a building foundation system, they are usually configured in groups to support continuous mat foundations or discrete pile caps for individual load-bearing elements. The impedance of a pile group cannot be determined by simple addition of individual pile impedances because grouped piles interact through the soil by "pushing" or "pulling" each other through waves emitted from their periphery. This is called a group effect, and it can significantly affect the impedance of a pile group as well as the distribution of head loads among individual piles in the group. Group effects depend primarily on pile spacing, frequency, and number of piles. They are more pronounced in the elastic range, and dynamic group effects decrease in the presence of material non-linearity. Numerical analysis methods of soil-pile-structure interaction (SPSI) problems can be classified into the following two approaches: direct method and substructure method. In the direct method for analysis of SPSI, it is necessary to model underlying soil, foundation, and structure with best precision and accuracy since they are supposed to be analyzed together. In the substructure method, soil-structure system is divided into the following two parts: the first part is the structure and the second part is the soil that has common boundary with the foundation and in which each part can be modeled in detail (Wolf 1985). In order to consider the influence of the piles on the dynamic response of the structure, the substructure method was used in this study. This consists of three consecutive steps:

(1) Calculation of foundation input motion in the absence of superstructure inertia (kinematic interaction) includes translational displacements and rotational components.

(2) Calculation of the dynamic impedances (spring and damping coefficients) for horizontal rotation and the combination of base foundation and pile system. 
(3) Calculation of the seismic response of the building supported on the springs and dashpots of step 2 and subjected at its base to the foundation input motion of step 1 .

The method of Fan et al. (1991), based on the BDWF model (Beam on Dynamic Winkler Foundation), is used to determine the foundation input motion. In this method, the displacement of the pile head (U11) as a function of the free-field motion (Uff) is calculated as follows:

$$
\mathrm{U}_{11}=\Gamma \mathrm{U}_{\mathrm{ff}}
$$

Here, $\Gamma$ is a function of spring and damping constants, frequency, and mechanical characteristics of the piles, such as $I p, A p, M p$, and $E p$.

A detailed study of gazetas shows that the kinematic factor $I u=U_{11} / U_{\text {ff }}$ for small frequencies, like the first frequency of the hospital Brig $(0.7 \mathrm{~Hz})$, is equal to 1 . This means no increase in the amplitude of the free-field earthquake motions. Therefore, in the case of the Brig hospital, the kinematic interaction effect was neglected.

The arrangement of pile-group in rectangular foundation is shown in Fig. 3. In this case, both rigid and flexible foundations are considered. In the fixedbase model, the structure is being analyzed without soil and foundation with fixed boundary condition to resist all displacements or rotations at the bottom.

In the cone model, the structure is built on a rigid foundation with springs and dashpots in the bottom in place of the soil. The response spectrum method was used for determining the displacements and accelerations.

To determine the vertical axial load in the upper part of the piles, a finite element model of the building was created using the ETABS program. In the modeling of the core, 3D shell elements were used. The elastic modulus $E$ of the concrete has been reduced to $60 \%$ of the design value to include the effects of cracking in the concrete. The $(q)$ factor (response factor) is set to 2 , and the importance factor is assumed as 1.4. In 2015, a new earthquake hazard map of Switzerland (Fig. 4) was issued with a corresponding design spectrum, which was used for the present study. The modal analysis was performed to determine natural modes of frequencies for the structural model in two different conditions, namely fixed-base behavior and behavior including SPSI (containing embedded piles with pile-group effect).

The results of ETABS analysis are given in Table 2, and the first vibration mode shape of the building with dynamic pile group effect obtained from the ETABS is shown in Fig. 5.

\subsubsection{Target Displacements}

The calculated target displacement in long and short directions according to the Euronorm 8 and ASCE 41-13, 2014, is found to be 12 and $15 \mathrm{~cm}$, respectively. These values represented the demand on the structure to have a sufficient ductility level under earthquake loads before a collapse of the building can occur. 


\subsubsection{Non-Linear Pushover Analysis}

A pushover analysis involves the application of static lateral loads distributed over the height of the structure and calculation of the resulting displacements in a

\begin{tabular}{|c|c|c|c|}
\hline$\#$ & Pile Type & Diameter $(\mathrm{Cm})$ & Length $(\mathrm{m})$ \\
\hline & 1 & 100 & 22 \\
\hline & 2 & 100 & 28 \\
\hline & 3 & 120 & 30 \\
\hline
\end{tabular}
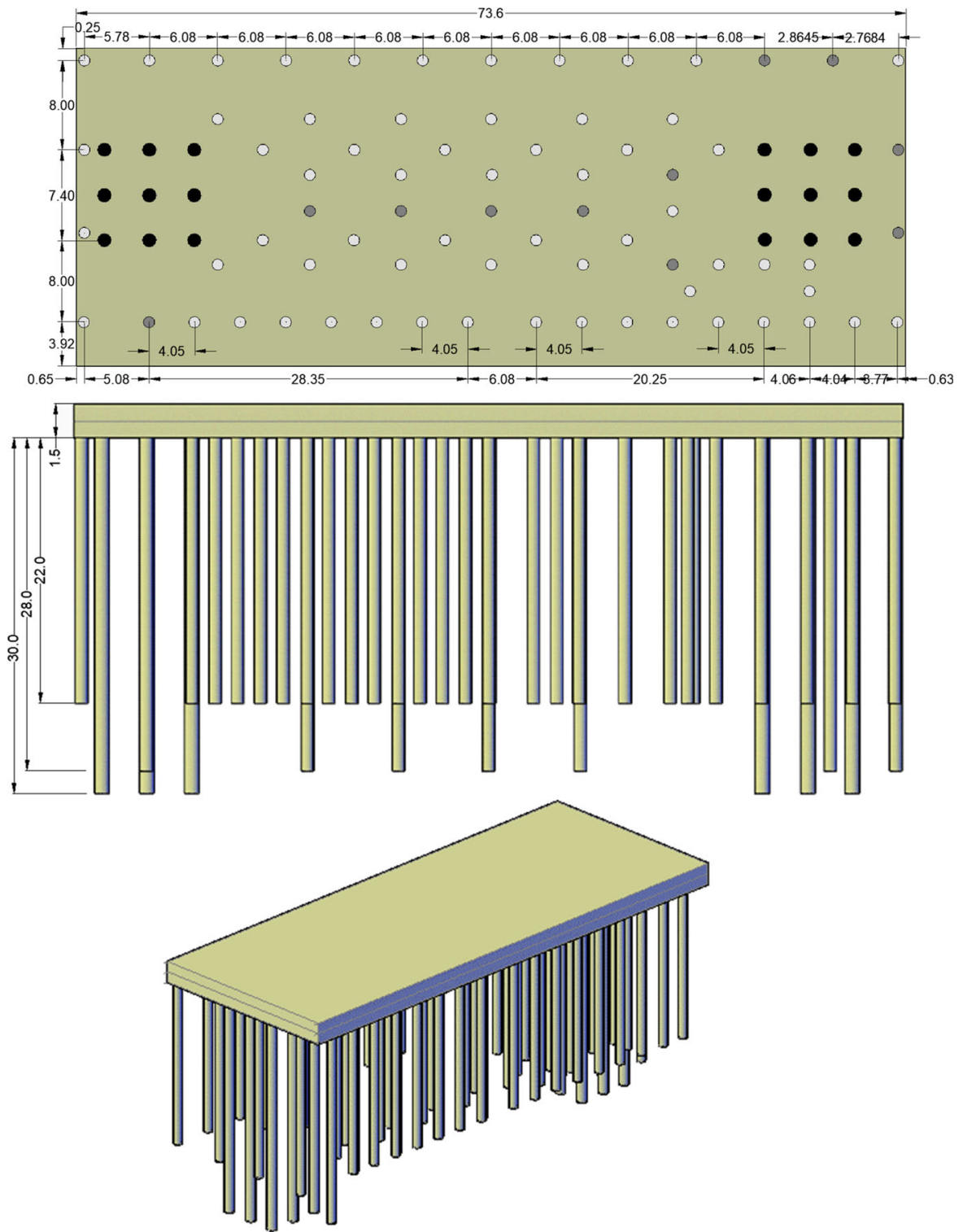

Fig. 3 The arrangement of pile group in rectangular foundation 


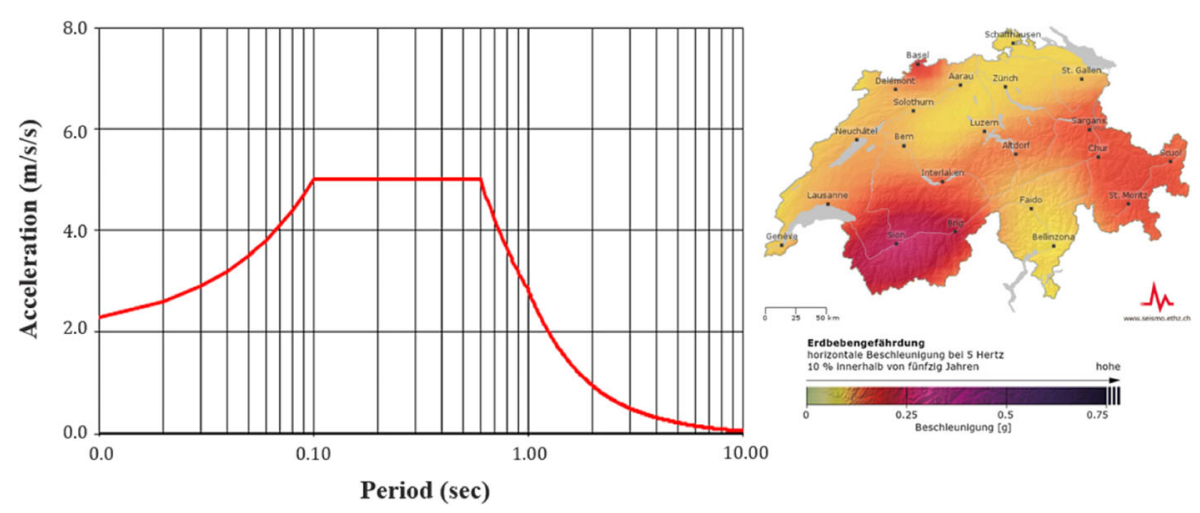

Fig. 4 The response spectrum for the Brig ground motion and the seismity map of Switzerland

model of the SPSI system. A pushover analysis of a structure with a flexible base is schematically illustrated in Fig. 6. A non-linear pushover analysis was reported for the reinforced concrete system model of the building with the parameters defined in ASCE 41-13. Behavior of each wall was determined based on the wall thickness, the wall length, and the material properties as provided by the ETABS model. At each point on the pushover curve, the deformations of all components in the structural system are related to the reference displacement. The ETABS model has been read into OpenSees for conducting the pushover analysis.

The pushover analysis resulted in displacement capacities of $20 \mathrm{~cm}$ in the transverse direction and $22 \mathrm{~cm}$ in the longitudinal direction, as shown in Fig. 7. This is compared with the target displacements, found from ASCE 41-13, of $12 \mathrm{~cm}$ in the longitudinal direction and $15 \mathrm{~cm}$ in the transverse direction.

\subsubsection{Dynamic Stiffness of Pile Groups}

Dynamic stiffnesses (spring and damping coefficients) for a pile group are strongly frequency-dependent. In the FCONE program reported in the article, the impedance matrix for different blocks (pile groups) was calculated as a function of frequency, using the cone model concepts according to John P. Wolf (Meek and Wolf 1994). For the determination of stiffness, a new method of solving dynamic interaction problems was developed wherein the seismic behavior of pile-soilpile-structure interaction (SPSI) system is investigated as a whole considering both pile group effect and soil constitutive model. As mentioned previously, modifications of the flexibilities have to be performed for modeling an embedded

Table 2 The results of two analyses obtained from the ETABS mode

\begin{tabular}{lll}
\hline & Period of vibration (s) & The roof displacement (cm) \\
\hline Fixed-base foundation (no piles) & 0.7 & 6.5 \\
Flexible foundation (including piles) & 1.2 & 11.5 \\
\hline
\end{tabular}




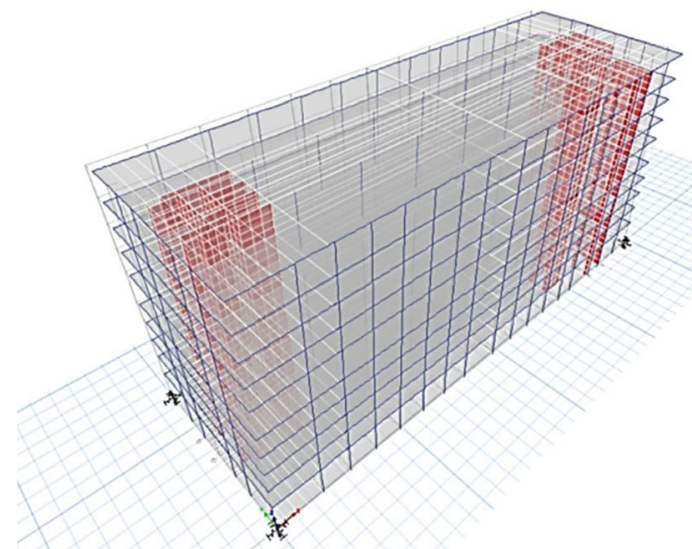

Fig. 5 The first vibration mode shape of the Brig structure (period: 1.195)

foundation since the double cone models (especially for the vertical degree of freedom) are too flexible at large distances from the loaded disk. The pile-soilpile interaction effect in the pile-group has been evaluated through the FCONE program by using the matrix of interaction factors $\left(\alpha_{v}\right)$, which is frequencydependent (Stacul and Squeglia 2018; El Naggar and El Naggar 2007). Results of the program for one $3 \times 3$ block under a core (i.e., spring and damper constants as a function of frequencies) are summarized in the following section.

The spectral values have been reduced to take account of the radiation and material damping of the soil. It turns out that in the case of the flexible-base structure, in addition to the added rocking component to the horizontal motion of the structure, a part of the structure vibration energy will transmit to the soil layer and can be dissipated. This results in a reduction of the natural frequency in comparison to the fixed-base model and an increase of the damping (mainly due to radiation damping resulting from the wave propagation and hysteresis damping of the soil materials).

Detailed mechanical characteristics of the soil have been explained in Table 3, where $E$ is elastic modulus, $G s$ is shear modolus, $\rho$ is unit weight, $C s$ is shear wave velocity, $v$ is Poisson's ratio, and $\xi$ is material damping ratio. The soil region was assumed to be homogeneous with uniform shear modulus and density during

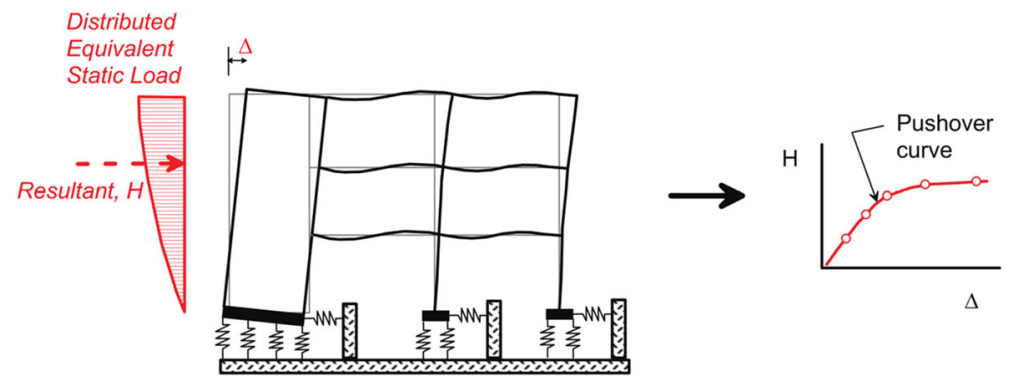

Fig. 6 Schematic illustration of a pushover analysis and development of a pushover curve for a structure with a flexible base (Stewart et al. 2012) 


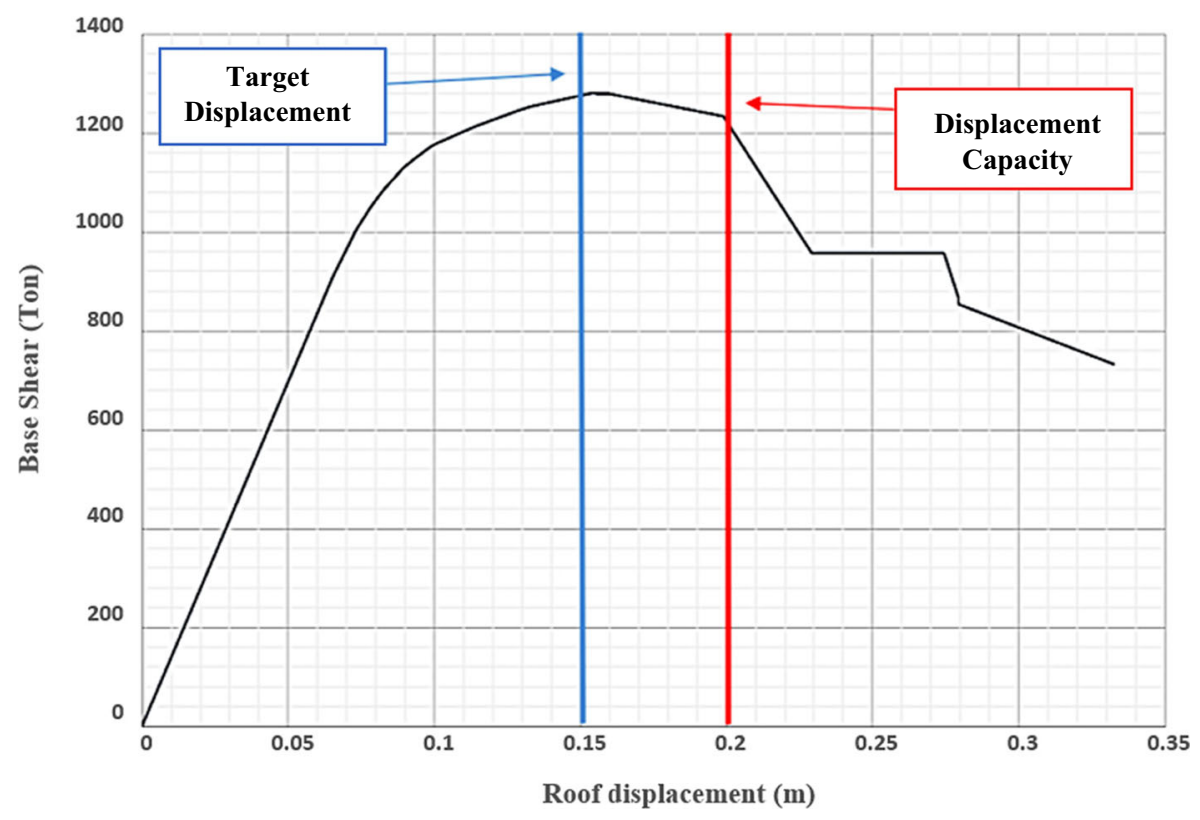

Fig. 7 The pushover curve obtained by OpenSees analysis

analysis (Stewart et al. 1999a; Stewart et al. 1999b). The horizontal, vertical, and rotational dynamic stiffness and damping ratios of a soil layer captured by using FCONE program are shown as a function of dimensionless frequency in Fig. 8.

The dynamic stiffness coefficients of an embedded foundation, such as a pile foundation, in a homogeneous half space are sensitive to variations in the soil material damping ratio, which is in turn a function of strain amplitude. In the lower frequency range $\left(a_{0}<1\right)$, considerable deviations exist for certain damping coefficient (Wolf and Deeks 2004; Meek and Wolf 1991). Figure 8b presents the dynamic behavior below and above the so-called cut-off frequency, where an abrupt change in response occurs. As can be seen in Fig. 8, the variation in damping coefficient at a lower frequency is much greater than that at a higher frequency.

\subsubsection{The Finite-Element Simulation}

The finite element code ABAQUS/Cae model as an accurate direct way was used to investigate the seismic behavior of the structure under the SPSI effect. For this purpose, the infinite soil medium is reduced to a finite region using infinite element boundaries. In this case, an elastic perfectly plastic model was adopted for modeling

Table 3 The mechanical characteristics of the soil

\begin{tabular}{lllllll}
\hline Parameter & $E(\mathrm{MPa})$ & Gs $(\mathrm{MPa})$ & $\rho\left(\mathrm{KN} / \mathrm{m}^{3}\right)$ & $C s(\mathrm{~m} / \mathrm{s})$ & $v$ & $\xi(\%)$ \\
\hline Quantity & 350 & 125 & 16.45 & 276.00 & 0.4 & 0.05 \\
\hline
\end{tabular}


the concrete piles with a modulus of elasticity of $30,000\left(\mathrm{~N} / \mathrm{mm}^{2}\right)$. In the 3D finite element model developed using Abaqus/Cae, both the pile and the soil were modeled using eight-nodded solid continuum elements (C3D8R) to account for the continuum nature of the soil. This element has a quadratic shape function which is well-suited to model the medium with bending-dominated deformation. A too

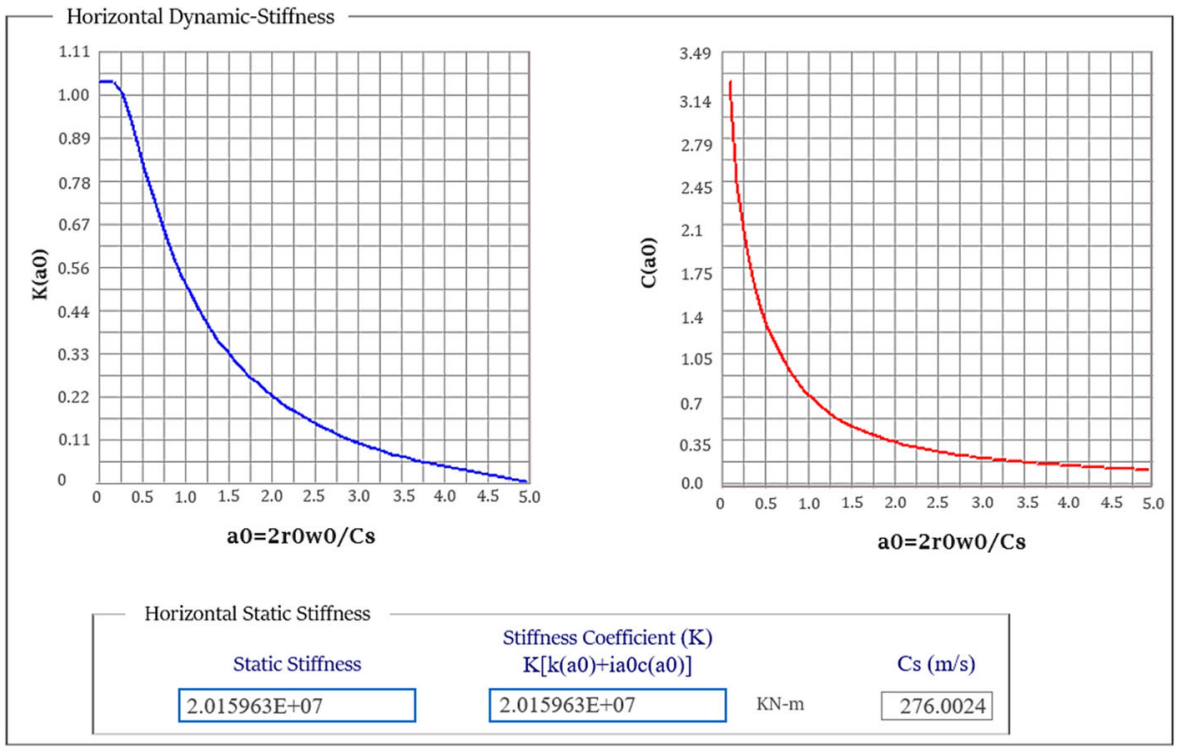

a) Horizontal Stiffness for a $3 \times 3$ Pile group

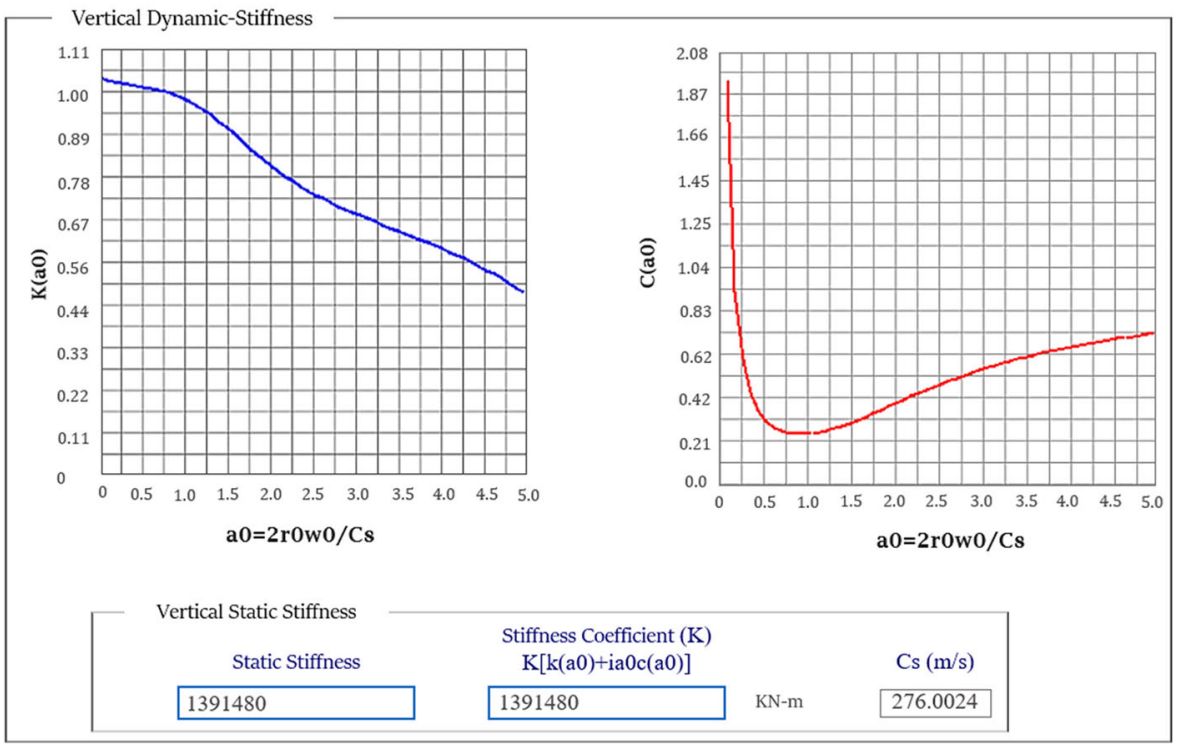

b) Vertical Stiffness for a $3 \times 3$ Pile group

Fig. 8 The vertical, horizontal, and rotational dynamic stiffness for a $3 \times 3$ pile group 


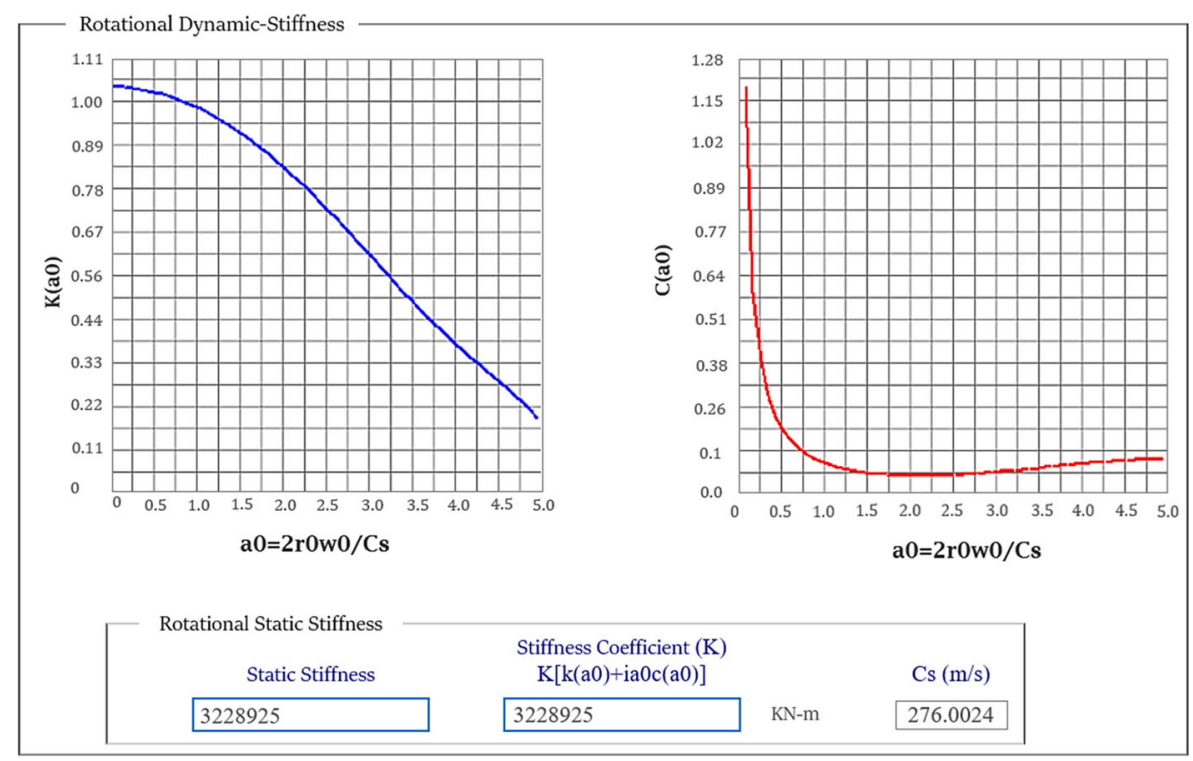

c) Rotational Stiffness for a $3 \times 3$ Pile group

Fig. 8 (continued)

coarse mesh may deviate from the expected response, whereas a too fine mesh requires very long computational time. Hence, a relatively fine mesh was adopted for the pile and a coarser mesh was adopted for the soil. Overall, 11,089 elements for the piles and 10,205 elements for 10-story SPSI model were used. The soil was modeled using 98,400 elements, and the soil-pile interaction was modeled by defining the tangential and normal behavior of the contact surfaces in the FE model (Ghandil and Behnamfar 2015; Bao et al. 2012).

A strain-hardening model using Mohr-Coulomb failure criterion was adopted for the soil which uses the five significant soil parameters, such as shear modulus $(G)$, Poisson's ratio $\left(v^{\prime}\right)$, shearing resistance angle $\left(\varphi^{\prime}\right)$, effective cohesion $\left(c^{\prime}\right)$, and angle of dilatancy $(\psi)$, as shown in Table 4 . An angle of internal friction of $35^{\circ}$ was used in the definition of the Mohr-Coulomb failure criterion. The geometrical details adopted for the SPSI analysis are shown in Fig. 9.

Results of 3D numerical prediction of first mode of vibration in eigenvalue analysis for both cases (fixed-base and SPSI interaction) and maximum lateral displacements in short direction are shown in Figs. 10 and 11, respectively.

Table 5 provides a good comparison between the results of SPSI analysis obtained by the cone method and FEM solution, which indicate that the results of the cone method are in close agreement with the FEM results. As the structural stiffness in comparison with soil or building height increases, the period rate increases as well. For the first mode of vibration in modal analysis, a good tendency with negligible difference was observed. Therefore, the cone model provided reasonable accuracy of modal analysis for the high-rise building responses because the deviation was limited to $3 \%$. 
Table 4 The soil parameters used in the finite element code ABAQUS/Cae model

\begin{tabular}{llll} 
Elastic parameters & & Plastic parameters (Mohr-Coulomb failure criterion) \\
\hline Mass density, $\rho\left(\mathrm{KN} / \mathrm{m}^{3}\right)$ & 16.45 & Shearing resistance angle, $\varphi^{\prime}$ & 34 \\
Modulus of elasticity, $E(\mathrm{MPa})$ & 350 & Angle of dilatancy, $\psi$ & 0.1 \\
Poisson's ratio, $v^{\prime}$ & 0.4 & Effective cohesion, $c^{\prime}(\mathrm{kPa})$ & 22 \\
\hline
\end{tabular}

From the comparison between the maximum lateral displacements, it can be observed that the foundation displacement results obtained from the cone method give good agreement with the FEM analysis results with about $6 \%$ difference, and the most difference was observed in the roof displacement with around $10 \%$. The non-linearity of the soil medium results in increased lateral displacements of stories; however, as can be seen by comparing the results, it does not have a significant impact on the lateral displacements in this case. It can be also concluded that the maximum lateral displacement of structures increases with the increasing number of stories, and the upper stories' displacements are more affected with SPSI than the lower stories.

\subsubsection{Dynamic Analysis of an Emergency Hospital in South of Switzerland}

Specification of the free-field ground motion is one of the most important factors in SPSI analysis. A range of intensities, durations, and frequency contents was covered by selecting the ground motions to enable a comprehensive evaluation of the SPSI effect. In this research, the used earthquake excitation was the $1940 \mathrm{El}$ Centro earthquake which has peak ground acceleration (PGA) of $0.349 \mathrm{~g}$, commonly used in structural dynamics. The ground motion records aligned in the two horizontal directions (shown in Fig. 12) were selected from the strong motion database of the Pacific Earthquake Engineering Research Center (PEER 2012).

The time history analysis was about $50 \mathrm{~s}$ duration consisting of 2500 steps under an actual earthquake accelerogram and a free vibration segment of $0.02 \mathrm{~s}$
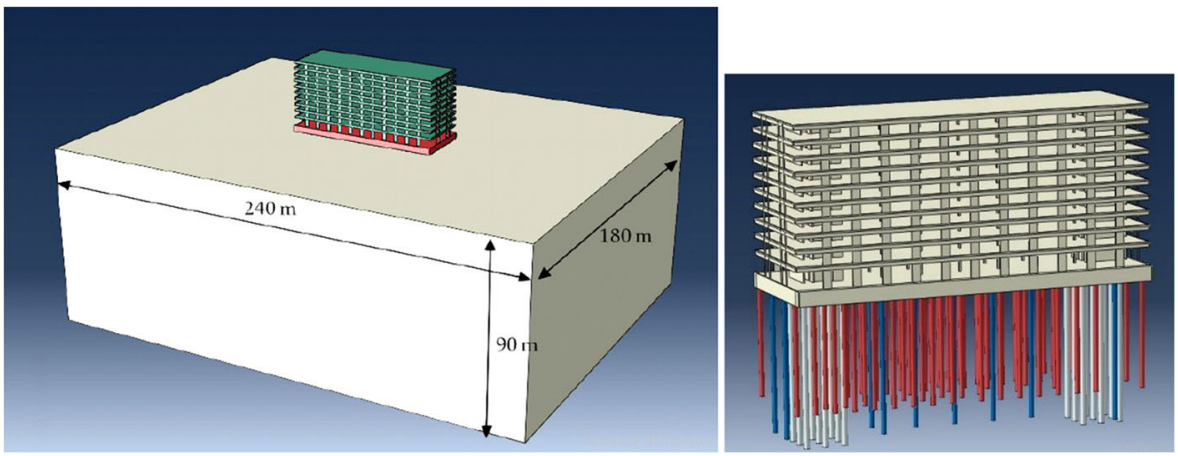

Fig. 9 The geometrical details of the SPSI model using ABAQUS/Cae 

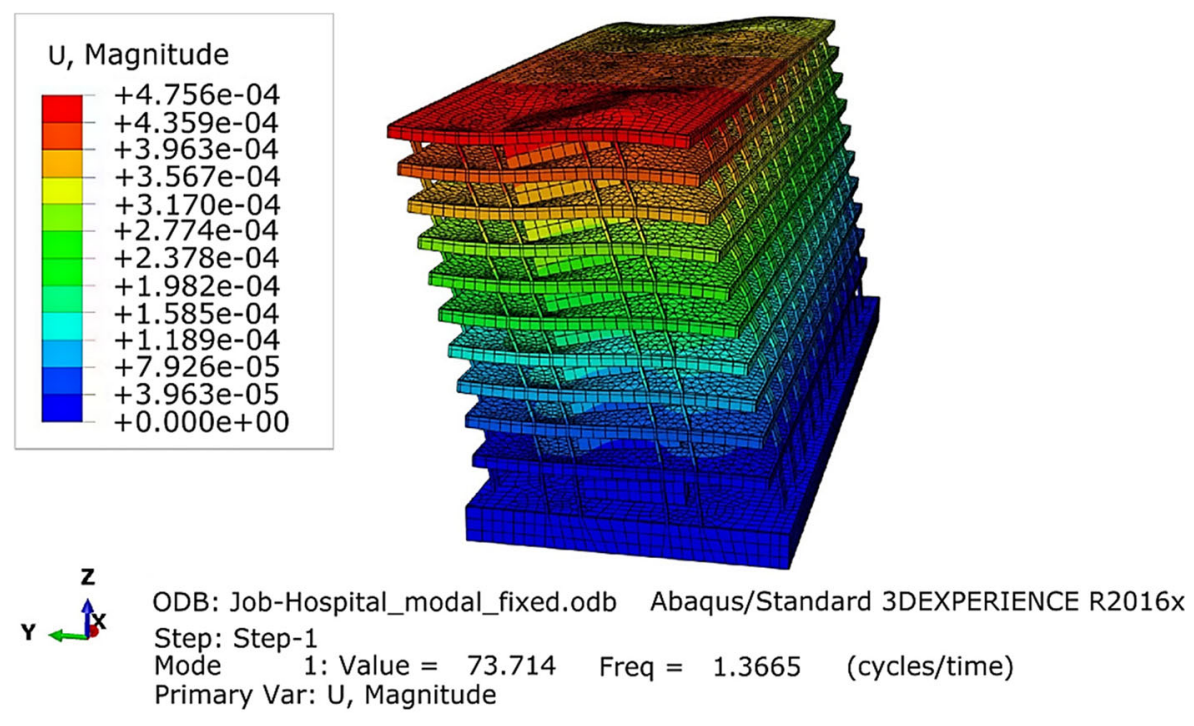

(a) Fixed base behavior (period of vibration: 0.73)

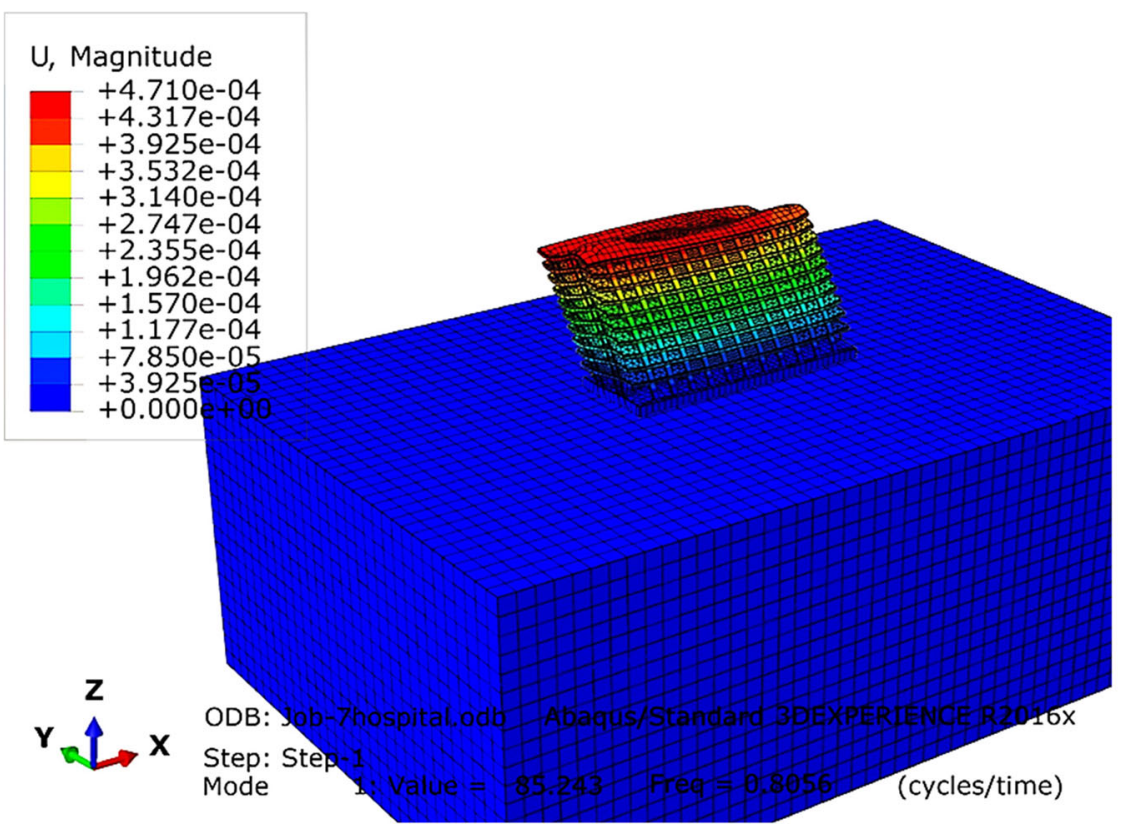

(b) SPSI analysis (period of vibration: 1.24)

Fig. 10 The first mode of vibration in eigenvalue analysis

duration. A comparison was made between the non-linear structural response of the rigid foundation and flexible foundation models subjected to time history analysis. Under the ground-motion record, the maximum lateral deflections at all 


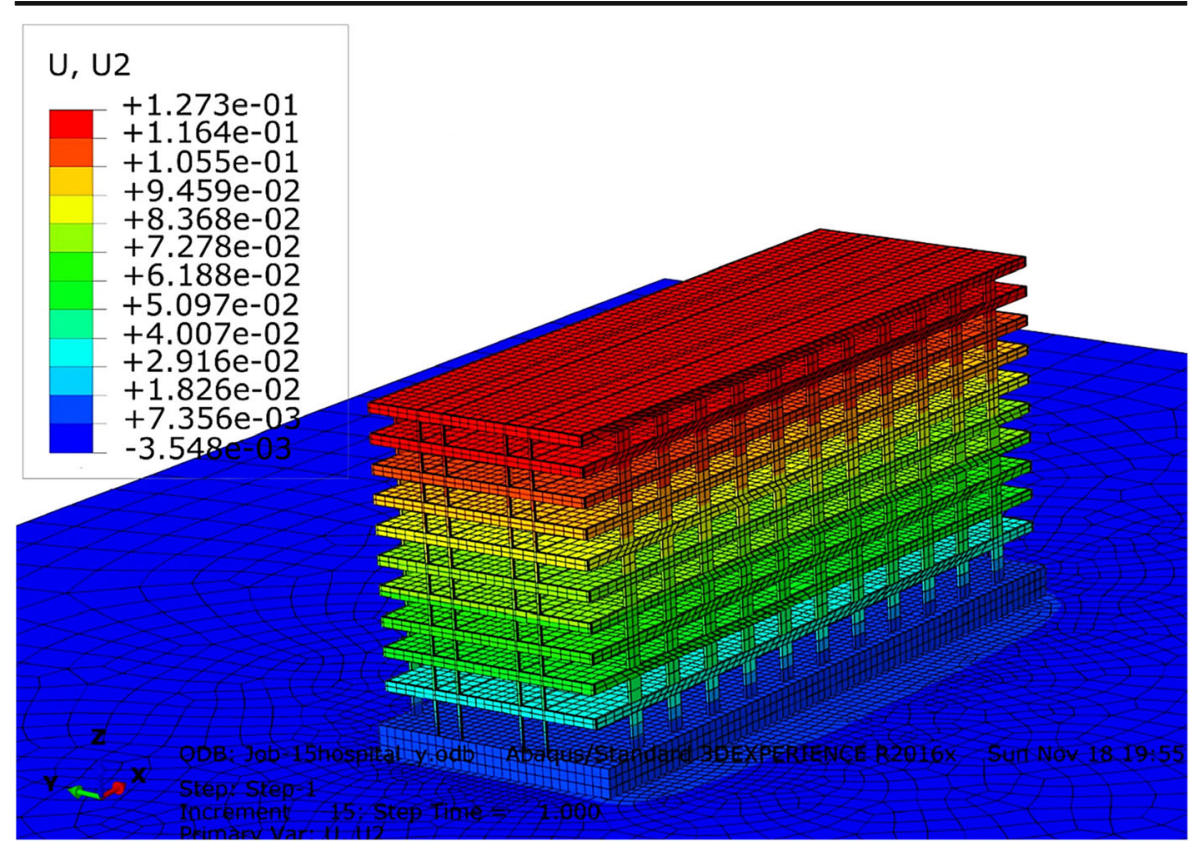

Fig. 11 The maximum lateral displacements in short direction

stories of fixed-base and flexible models were measured by using the ETABS program. As mentioned, the significance of the displacement mechanisms was expected to depend on the excitation, soil, and structure properties. In particular, lateral displacements and story drifts of the structures resting on rather soft soils may be significantly amplified by SPSI (Jennings and Kuroiwa 1968).

The time histories of roof displacements under earthquake excitation with SPSI effect along $\mathrm{X}$ and $\mathrm{Y}$ directions are demonstrated in Fig. 13. In addition, the maximum lateral displacements and story drifts in both cases are shown versus the building floors in Fig. 14 (parts a and b) and (parts c and d), respectively.

From the comparison, it can be observed that the top deflection of the 9th-floor building (roof) with SSI effect increased by 1.77 times (and 2.12 times) than the case without taking into consideration the SSI effect, along the $\mathrm{X}$ direction (and the $\mathrm{Y}$ direction), respectively.

It should be noted that soil-structure interaction analysis typically involves dealing with several uncertainties. The results of such dynamic analysis may require determining the limitation of material properties and models. In real engineering projects, the

Table 5 Comparison between the results of SPSI analysis obtained by the cone method and FEM solution

\begin{tabular}{llllll}
\hline & \multicolumn{2}{l}{ The period of vibration (s) (first mode) } & & \multicolumn{2}{l}{ The lateral displacement in short direction $(\mathrm{Cm})$} \\
\cline { 2 - 3 } & Fixed base & SPSI & & Foundation & The roof story \\
\hline Cone model & 0.7 & 1.20 & 0.28 & 11.50 \\
FEM model & 0.73 & 1.24 & 0.30 & 12.73 \\
\hline
\end{tabular}



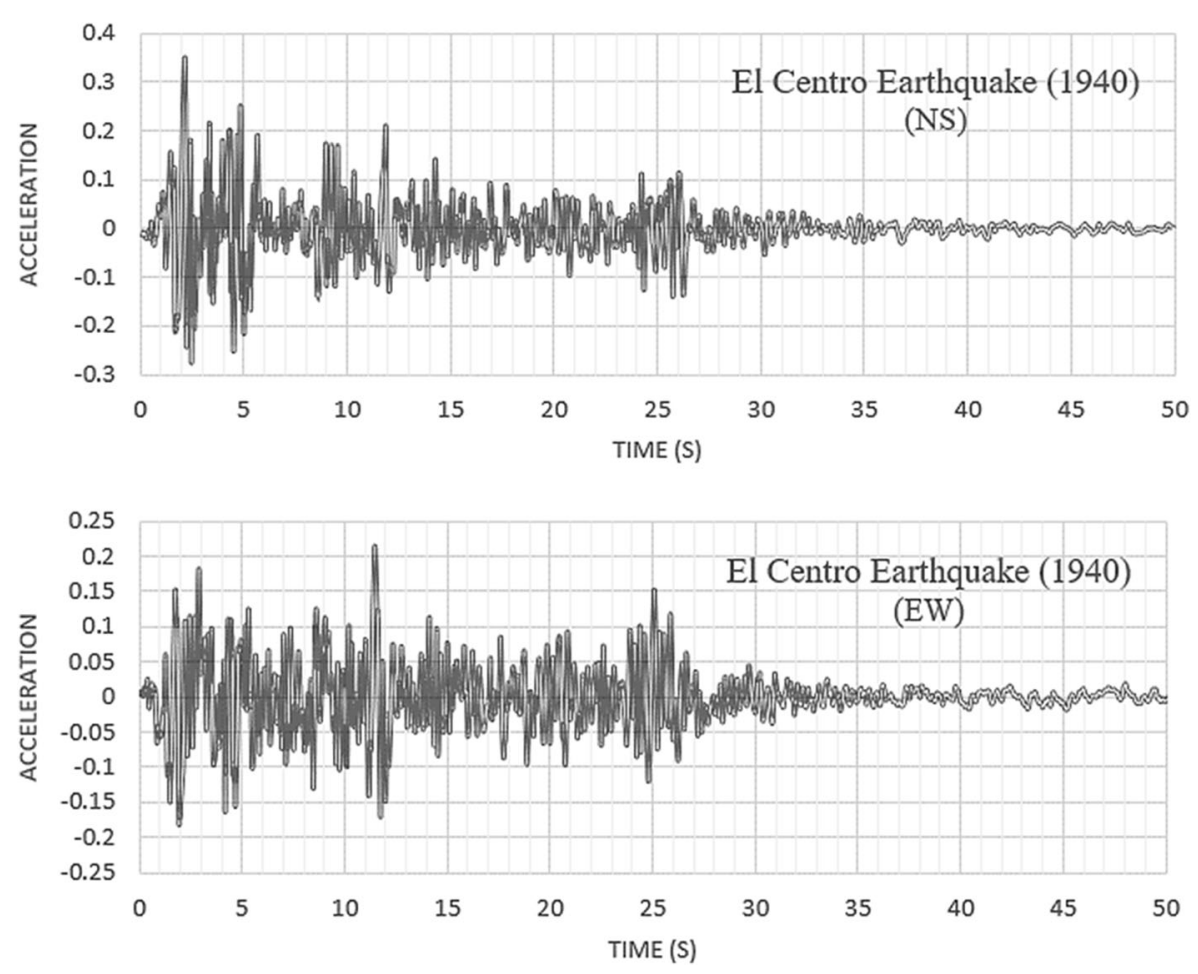

Fig. 12 Earthquake excitation: the El Centro earthquake in two horizontal direction (NS and EW)

limitation ranges are determined in such a way that they stay on the conservative side. The uncertainties have remarkable impact on the structure response, and, hence, it is essential to be cautious in this matter.

\section{Case Study 2: Dynamic Analysis of the Green Building at MIT Campus}

The Green building is Building 54 at the MIT campus in Cambridge, Massachusetts, USA. This building is the tallest structure in Cambridge, designed and

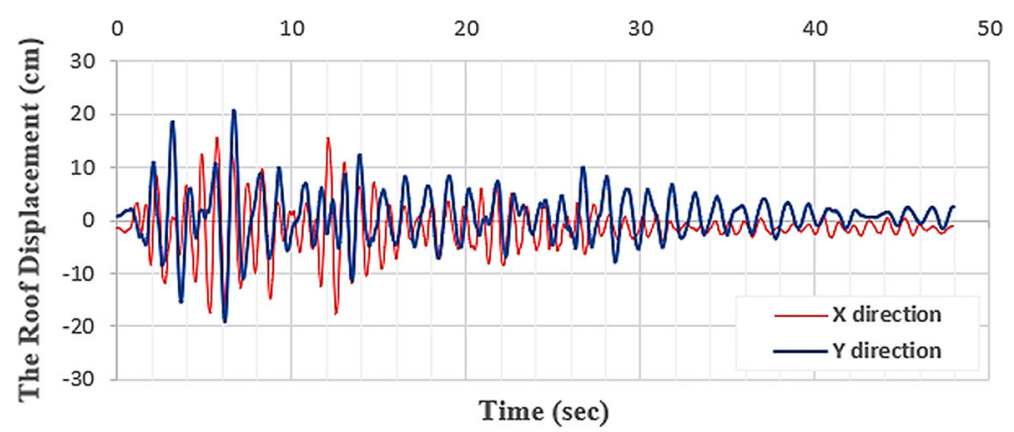

Fig. 13 The roof displacements along $\mathrm{X}$ and $\mathrm{Y}$ directions 


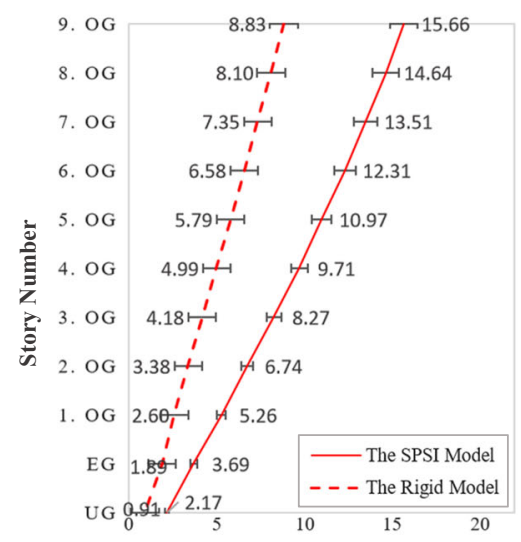

(a) Maximum lateral deflections (cm) (in $\mathrm{X}$ direction)

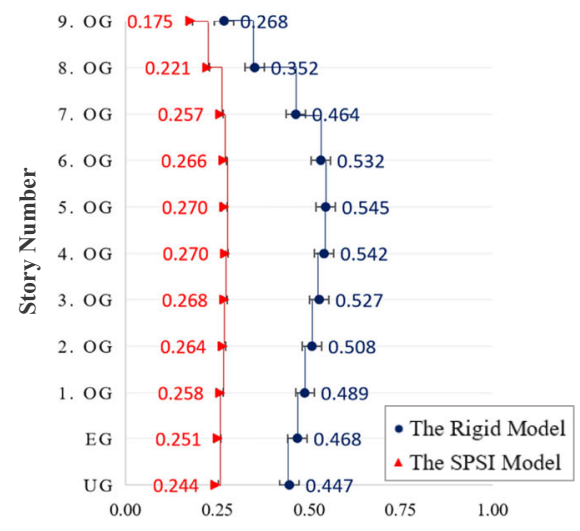

(c) The Story Drift (\%) (in $\mathrm{X}$ direction)

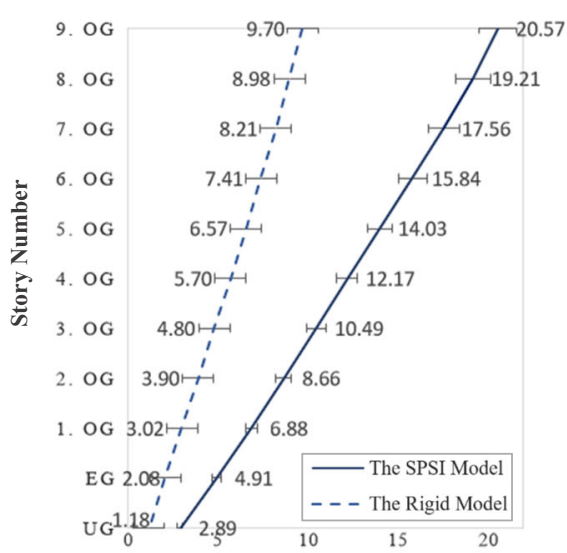

(b) Maximum lateral deflections (cm) (in $\mathrm{Y}$ direction)

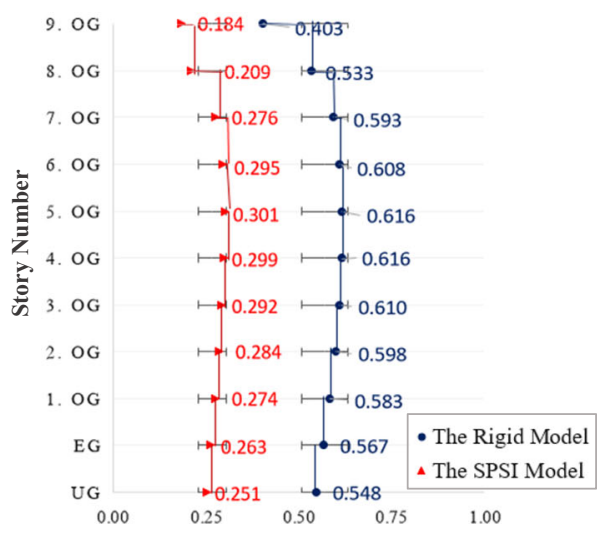

(d) The Story Drift (\%) (in $\mathrm{Y}$ direction)

Fig. 14 The maximum lateral deflections: (a) in X direction and (b) in Y direction and The Story drifts drifts: (c) in $\mathrm{X}$ direction, (d) in $\mathrm{Y}$ direction

constructed by I.M. Pei from 1962 to 1964 and came into operation at 1964. In the plan, this building has the dimension of $34 \times 16.5 \mathrm{~m}$. It has 20 stories with an overall height of $83 \mathrm{~m}$ plus a one-story basement below ground level. The height of the first story is $10 \mathrm{~m}$, and that of the others is $3.5 \mathrm{~m}$. The ground surface is approximately $6.1 \mathrm{~m}$ above sea level, and depth to bedrock is approximately $30.55-$ $40.0 \mathrm{~m}$ below sea level. Building 54 includes administrative sections and classrooms for Natural Sciences department. As shown in Fig. 15, the building orientation in the plan has a deviation of $25^{\circ}$ to the north. Two $25-\mathrm{cm}$-thick shear walls extend from the basement-foundation level to the roof level at the two narrow ends. The underground floor has a link to the MIT colleges' connecting tunnel. The structure was made of cast-in-place reinforced concrete, and the thickness of the concrete slab at each story is $101 \mathrm{~mm}$. 


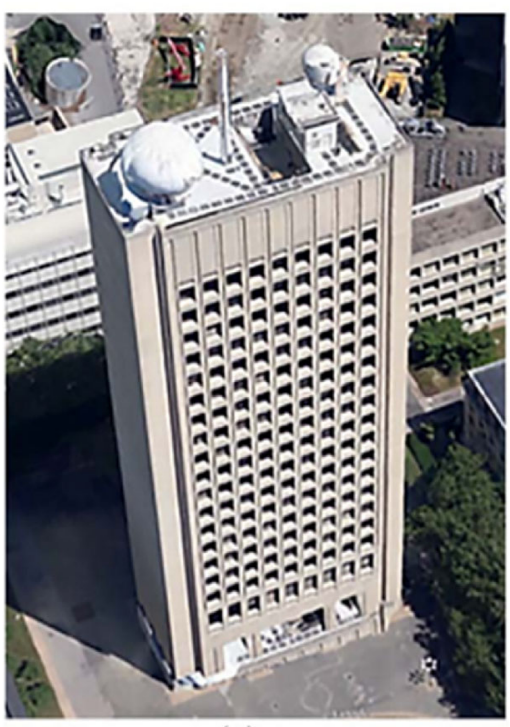

(a) (b)
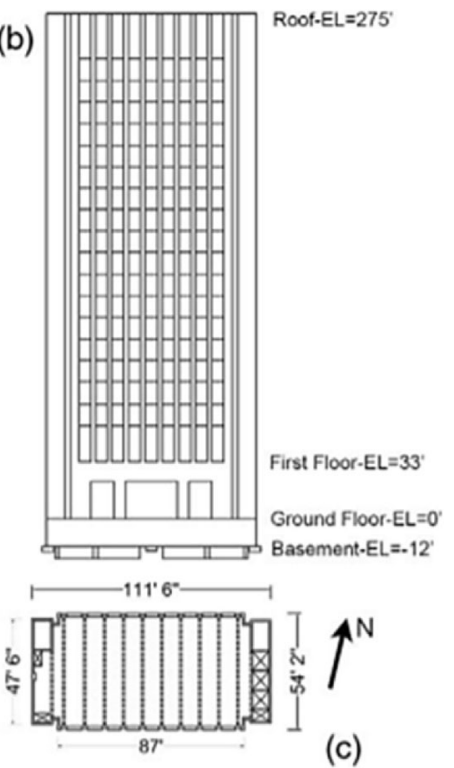

Fig. 15 Image of Green building at the MIT campus, Cambridge

In Fig. 16, the position of the shear walls, the dimensions, and the sizes are specified. The building is placed on a concrete mat foundation with concrete pile caps that have thickness of $350 \mathrm{~mm}$ and loading capacity of 50 tons. The foundation dimension is $34 \times 16.5 \mathrm{~m}$. Despite the existence of doors, windows, and entrances, from the shear walls up to the roof level, the building still could be considered as a symmetric structure. Figure 17 shows a typical depth versus shear wave velocity $\log$ from a site approximately $50 \mathrm{~m}(150 \mathrm{ft})$ from the building (Jen 2011; Haley and Aldrich 1983).

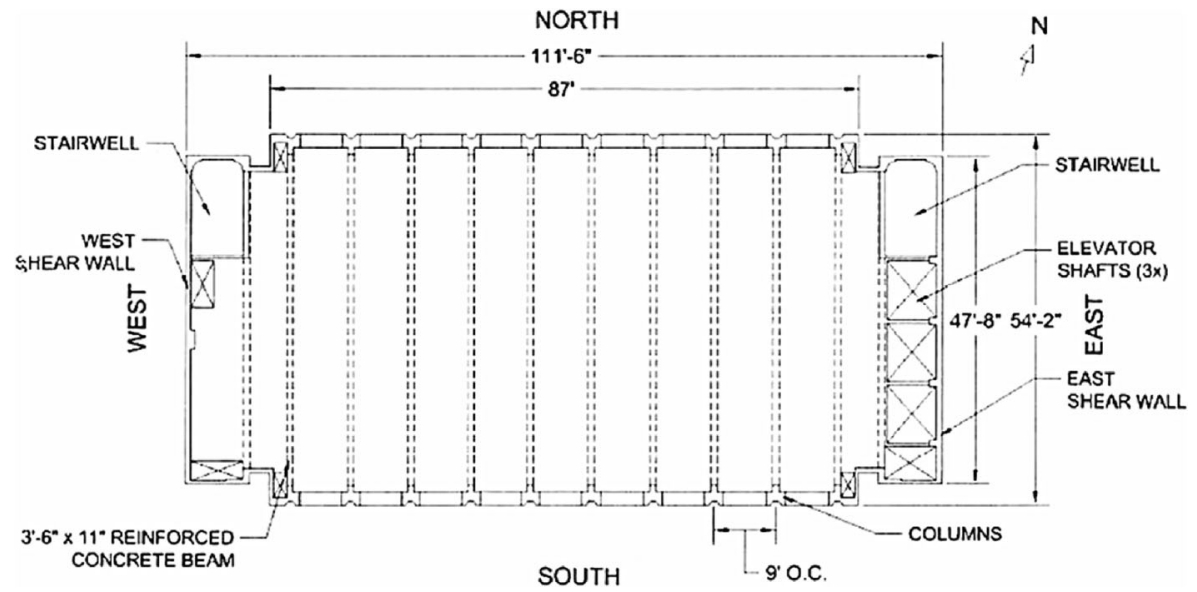

Fig. 16 The plan view of the building depicting the distribution of shear walls 


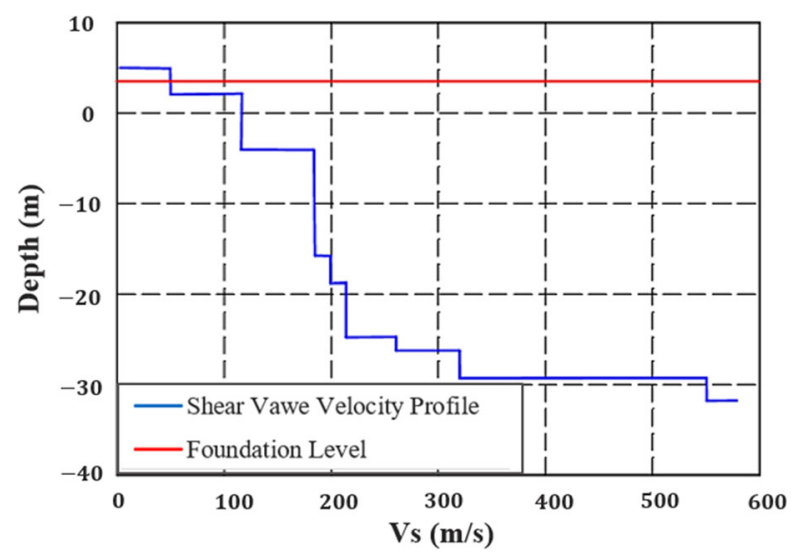

Fig. 17 Shear wave velocity log versus depth profile of the site

\subsection{Site Condition}

Building 54 is located near the Charles River. The structure is placed on the alluvial deposits of the river. Geotechnical studies of the site condition have been thoroughly performed, and the soil properties, especially shear wave velocity of the soil, were determined.

The site was $6.1 \mathrm{~m}$ above mean sea level, and, according to geotechnical studies, the shear wave velocity varied between 100 and $600 \mathrm{~m} / \mathrm{s}$. The depth of bedrock was estimated to be around 30.55 to $34 \mathrm{~m}$ from the ground surface. Based on a shear wave velocity boring $\log$ from a site approximately $50 \mathrm{~m}$ from the building (Jen 2011; Haley

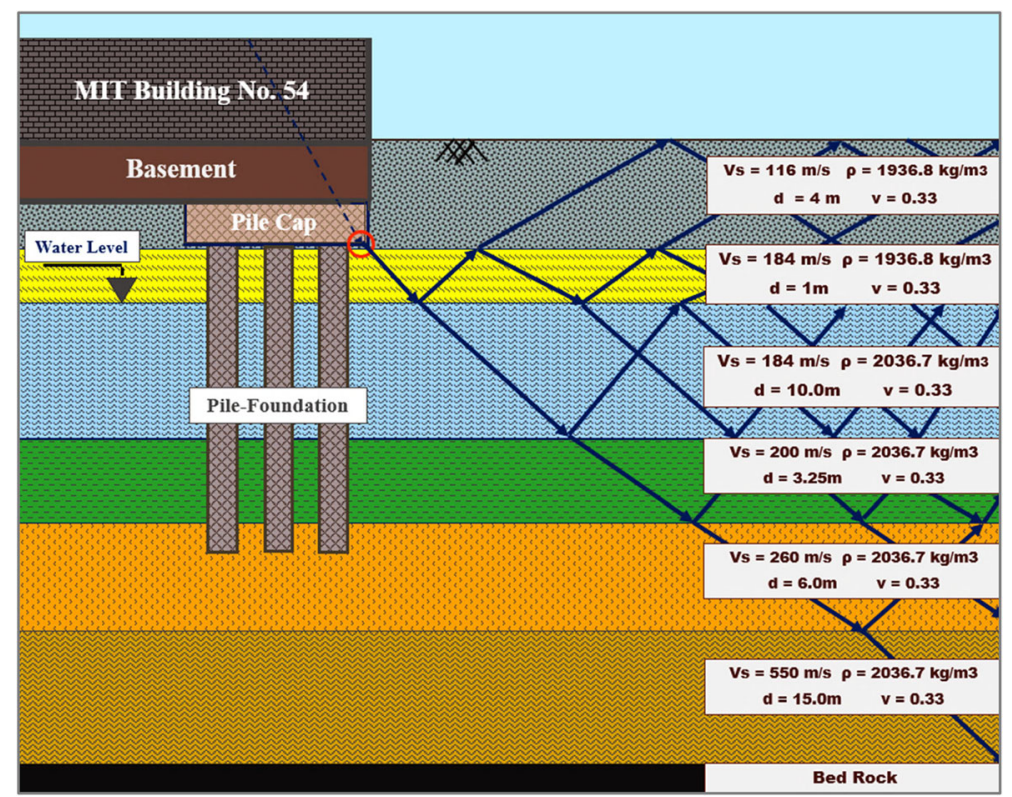

Fig. 18 The soil profile and the wave propagation in the soil layers 


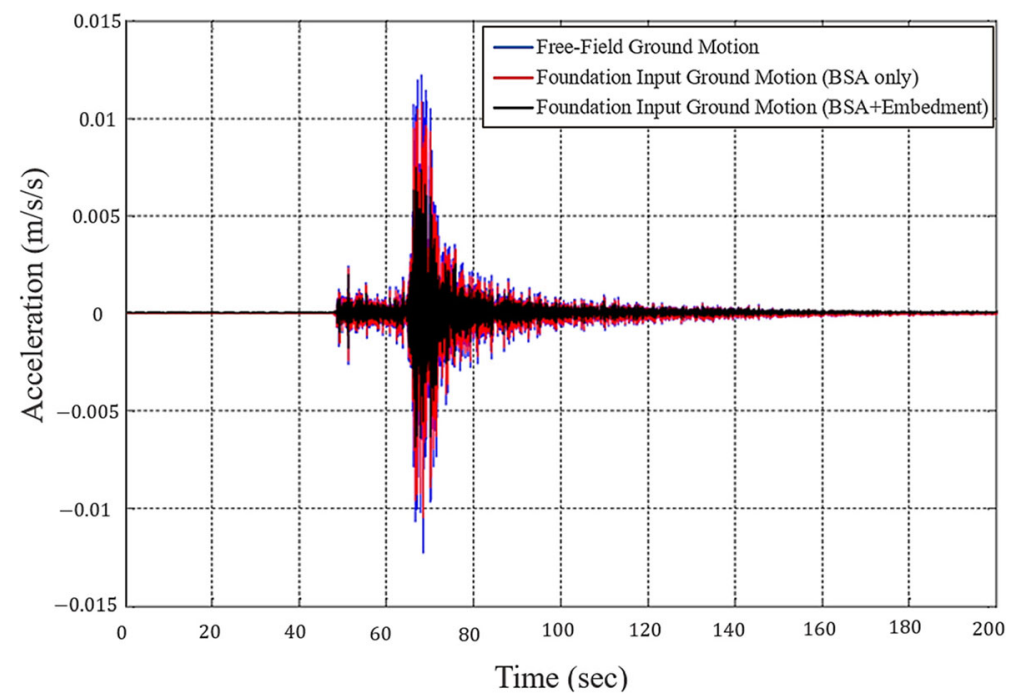

Fig. 19 The M4.0 Hollis Center earthquake (Maine) in free field, modified by BSA consideration and modified with both BSA and embedment effect

and Aldrich 1983), the fundamental site frequency is estimated to be $\sim 1.5 \mathrm{~Hz}$. Figure 18 displays the soil profile and the wave propagation in the soil layers. Later, Trocha (2013) studied the dynamic behavior of this building, again using ambient data. The natural frequencies were identified-with some differences from those identified by Çelebi et al. (2014) as $0.75 \mathrm{~Hz}$ (1st NS), $2.85 \mathrm{~Hz}$ (2nd NS), $0.68 \mathrm{~Hz}$ (1st EW), $2.45 \mathrm{~Hz}$ (2nd EW), and $1.45 \mathrm{~Hz}$ (1st Tor). The fundamental frequency of the building $(0.68 \mathrm{~Hz})$ is less than the frequency of the site; hence, no radiation damping is

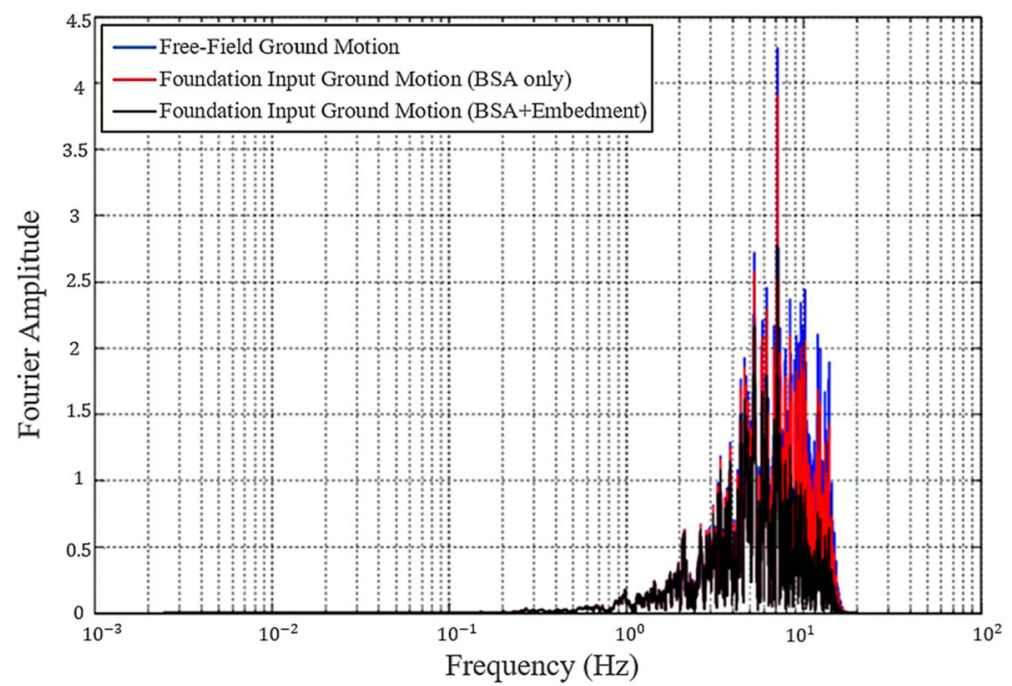

Fig. 20 Fourier transform of M4.0 Hollis Center earthquake (Maine), in which transfer function of BSA and embedment are multiplied 


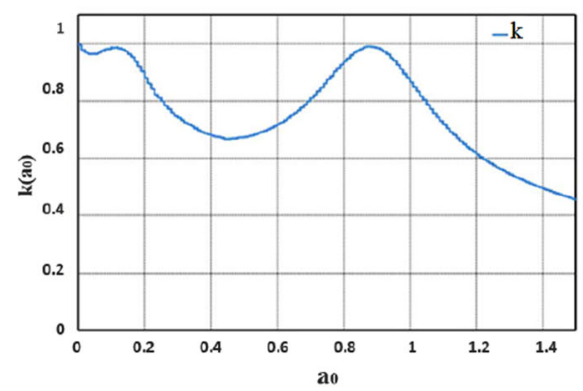

(a)

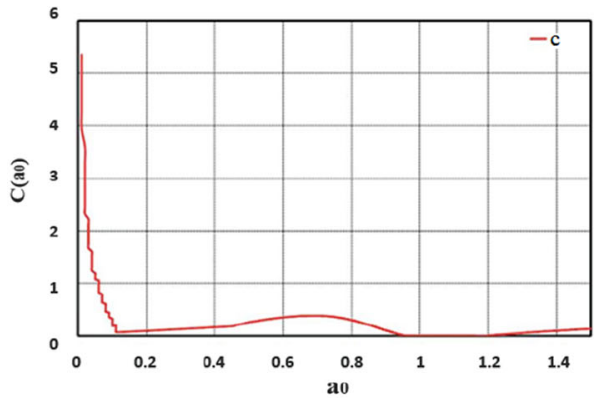

(b)

Fig. 21 Dynamic soil stiffness calculated with FCONE program for horizontal degree of freedom: (a) spring coefficient and (b) damping coefficient

considered. In addition to geotechnical data, the site seismicity data were also available. In 2012, the magnitude 4.0 earthquake occurred near Hollis Center, Maine, where data recorded with accelerometers were available. In the present study, three ground motions including recorded ground motion in Boston resulting from (October 16, 2012) Hollis Center Earthquake, Imperial Valley (El Centro in 1940) earthquake and employed ground motion in the rehabilitation of Hotel Azadi, Tehran, Iran are considered as the input motions for the dynamic analysis and structure evaluation.

\subsection{Modeling and Dynamic Analysis}

The modeling of Building 54 has been performed in detail, meaning that the structure was simulated along with the surrounding soil. Computation of maximum lateral displacement for all stories of the building corresponding to the soft soil during the three mentioned earthquakes was done based on both conditions with and without SSI. Although the structure data were clear and definite, there was considerable uncertainty in soil properties which caused complex challenges in the analysis. The "springs and dashpots" method proposed by the NEHRP Seismic Provisions (Stewart et al. 2012) allows evaluating the mechanical and dynamical characteristics of soil that have been impacted by a combination of three mechanisms, including footing conditions,

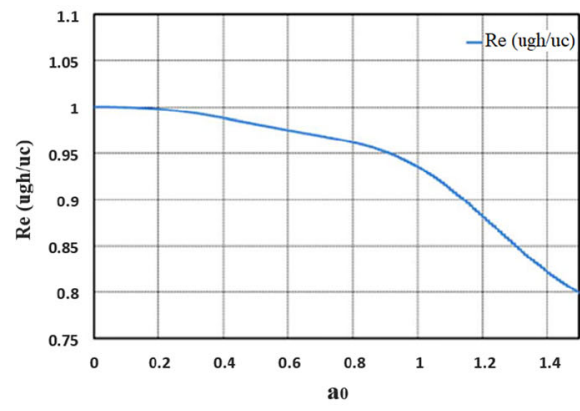

(a)

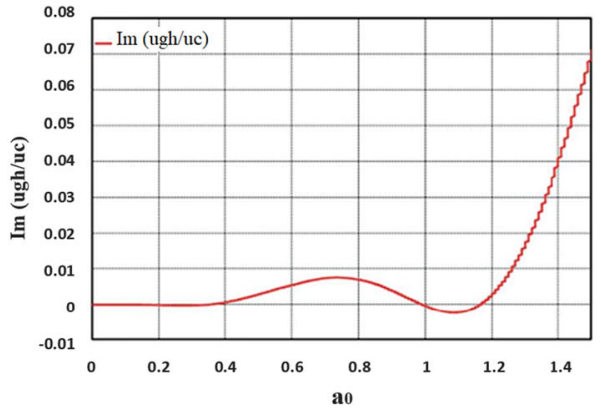

(b)

Fig. 22 Effective foundation input calculated with FCONE program for horizontal degree of freedom: (a) real component and (b) imaginary component 


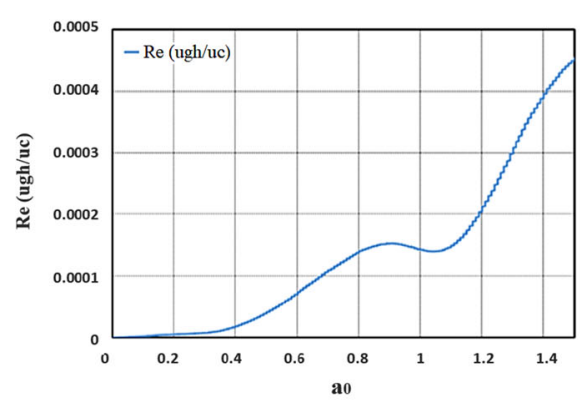

(a)

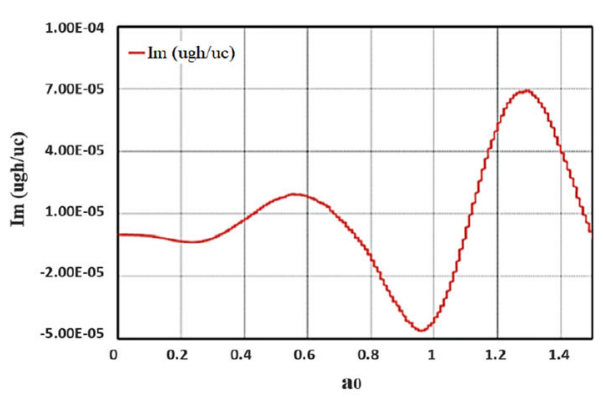

(b)

Fig. 23 Effective foundation input calculated with FCONE program for rocking degree of freedom

embedment effects, and pile contributions. On the basis of the approach described previously, 160 nodes are considered at the base level, and resultant of footing and pile stiffness are distributed on the nodes in the base level.

The MIT building has a mat foundation with $34.0 \mathrm{~m}$ in length and $20.5 \mathrm{~m}$ in width, which is supported by pile groups. Pile groups are fixed with pile caps located at both longitudinal directions of the building (i.e., EW side). The length of the piles is $15 \mathrm{~m}$, and their diameter is $0.3556 \mathrm{~m}$, and each group contains 30 piles. In order to capture the soil-structure interaction effects, it would be needed to consider combined response of mat foundation and pile groups.

Kinematic interaction due to existence of stiff elements causes recorded ground motions in the free field to be significantly less than what is imposed to the foundation. The main reasons associated with this phenomenon are the base-slab averaging (BSA),
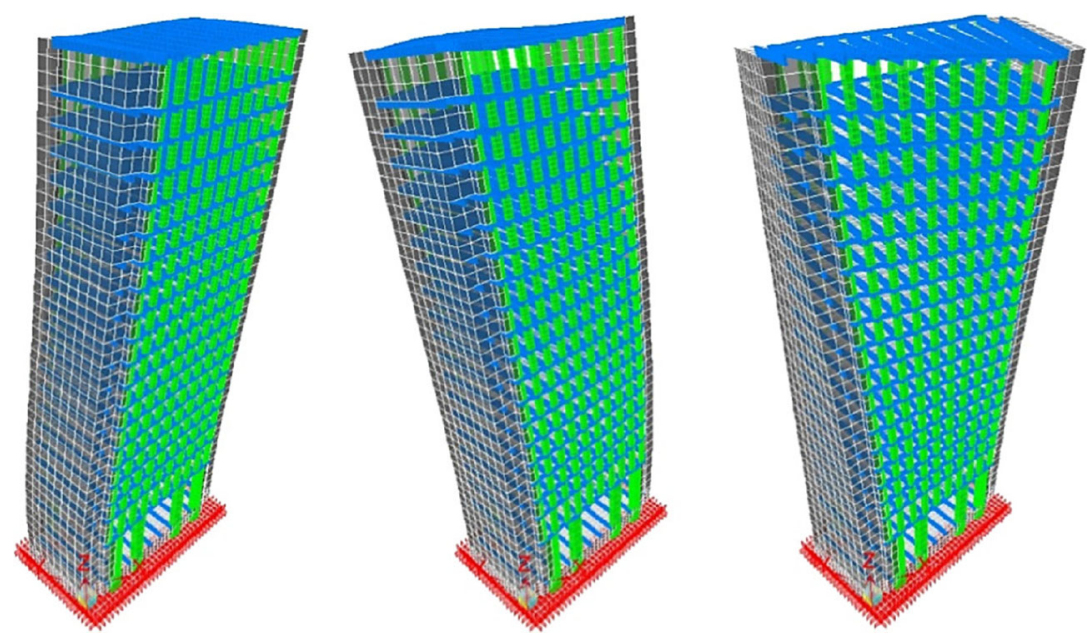

\begin{tabular}{|c|c|c|c|}
\hline $\begin{array}{c}\text { Mode } \\
\text { No. }\end{array}$ & $\begin{array}{c}\text { Period Fixed-Based } \\
\text { ETABS Model (sec) }\end{array}$ & $\begin{array}{c}\text { Period Flexible-Based } \\
\text { ETABS Model (sec) }\end{array}$ & $\begin{array}{c}\text { Period Çelebi } \text { et al. } \\
\text { (sec) }\end{array}$ \\
\hline 1 & 1.3793 & 1.5319 & 1.47 \\
\hline 2 & 0.9883 & 1.0938 & 1.33 \\
\hline 3 & 0.5892 & 0.6303 & 0.4 \\
\hline
\end{tabular}

Fig. 24 The first three identified mode shapes obtained from the ETABS analysis 
Table 6 The roof displacements under excitation of three considered ground motions with and without SSI effect

\begin{tabular}{llllllllll}
\hline & \multicolumn{3}{l}{ Flexible-base model $(\mathrm{Cm})$} & & \multicolumn{3}{l}{ Fixed-base model $(\mathrm{Cm})$} \\
\cline { 2 - 4 } \cline { 6 - 9 } & Min. Y & Max. Y & Min. X & Max. X & & Min. Y & Max. Y & Min. X & Max. X \\
\hline Hollis Center & -0.0468 & 0.055 & -0.0402 & 0.0377 & -0.06 & 0.0547 & -0.0397 & 0.0365 \\
Hotel Azadi & -29.408 & 31.915 & -30.7 & 36.7 & -20.94 & 20.26 & -34.4 & 35.7 \\
El Centro & -15.695 & 20.12 & -28 & 28.2 & -20.63 & 20.64 & -17.5 & 17.7 \\
\hline
\end{tabular}

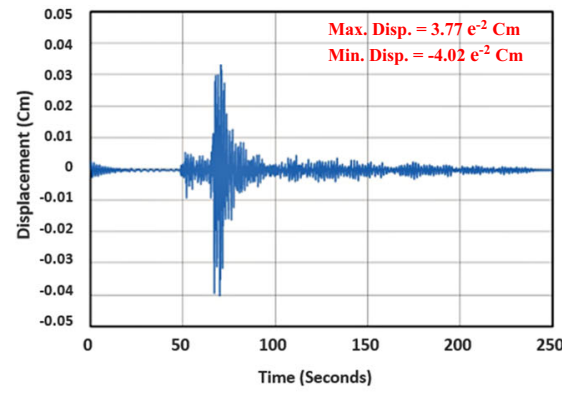

(a) Flexible-based Model

Hollis center earthquake (in X-direction)

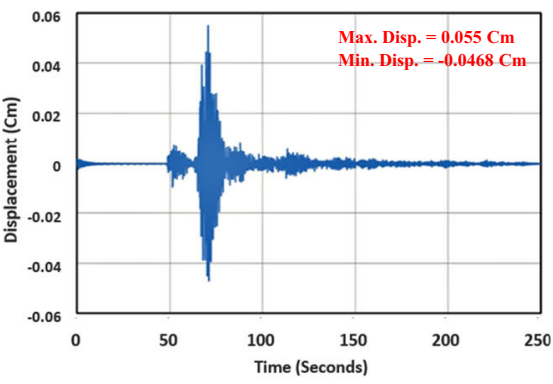

(c) Flexible-based Model

Hollis center earthquake (in Y-direction)

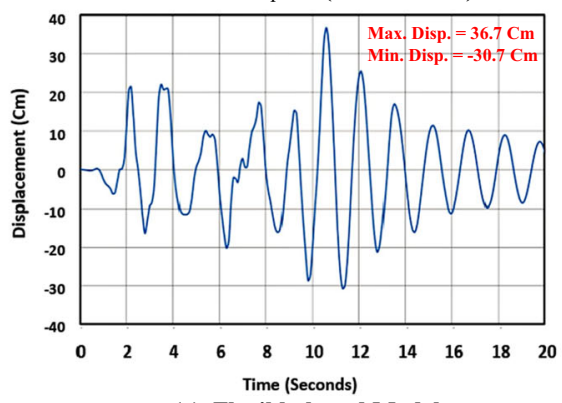

(a) Flexible-based Model Hotel azadi earthquake (in X-direction)

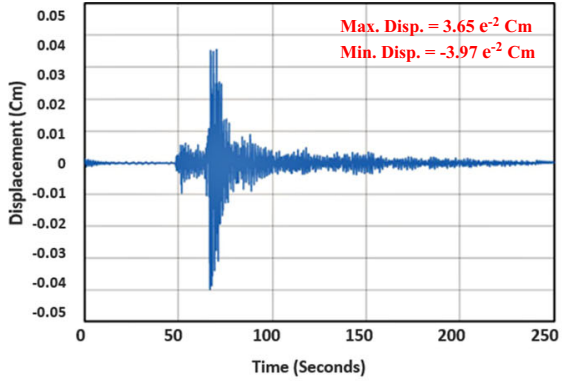

(b) Fix-based Model

Hollis center earthquake (in X-direction)

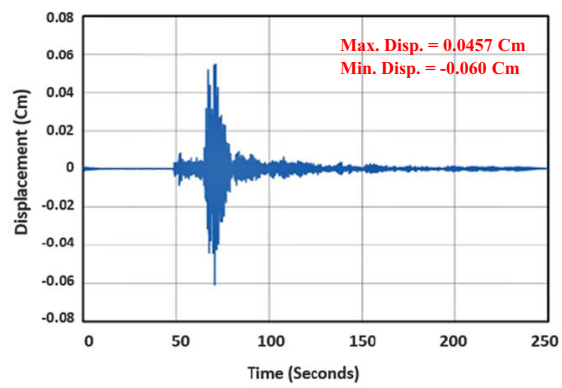

(d) Fix-based Model

Hollis center earthquake (in Y-direction)

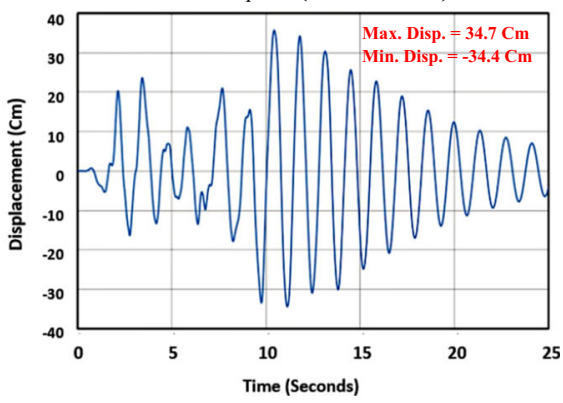

(b) Fix-based Model

Hotel azadi earthquake (in X-direction)

Fig. 25 The roof displacements under excitation of three considered ground motions with and without SSI effects 


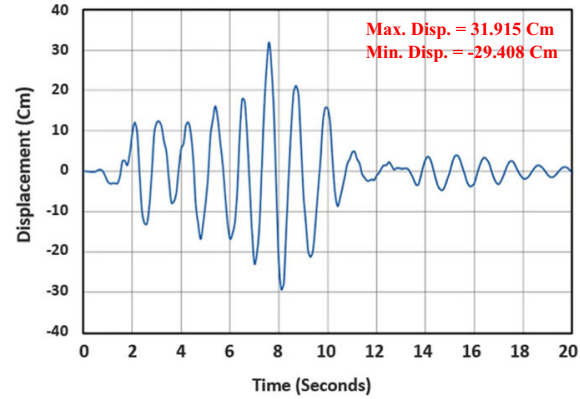

(c) Flexible-based Model

Hotel azadi earthquake (in Y-direction)

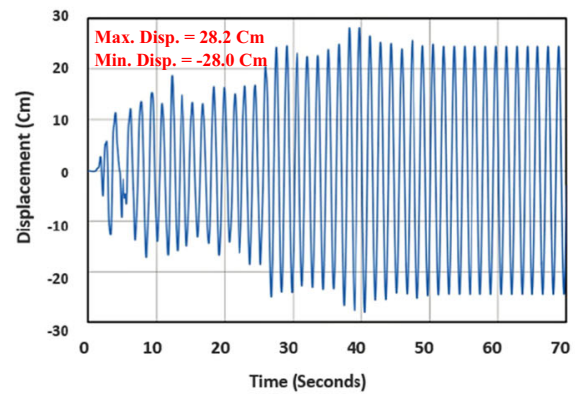

(a) Flexible-based Model

El Centro earthquake (in X-direction)

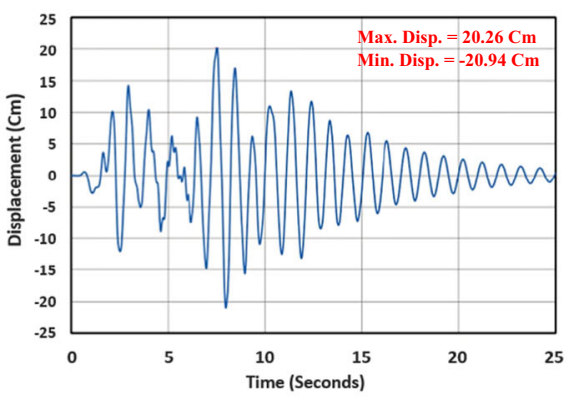

(c) Flexible-based Model

El Centro earthquake (in Y-direction)

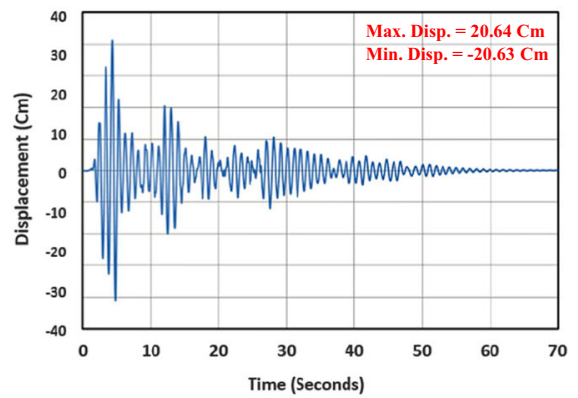

(d) Fix-based Model

Hotel azadi earthquake (in Y-direction)

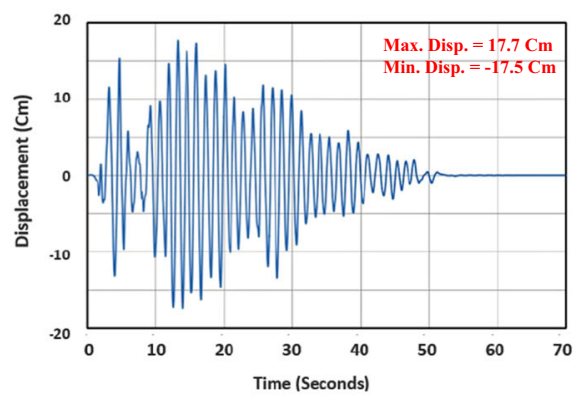

(b) Fix-based Model

El Centro earthquake (in X-direction)

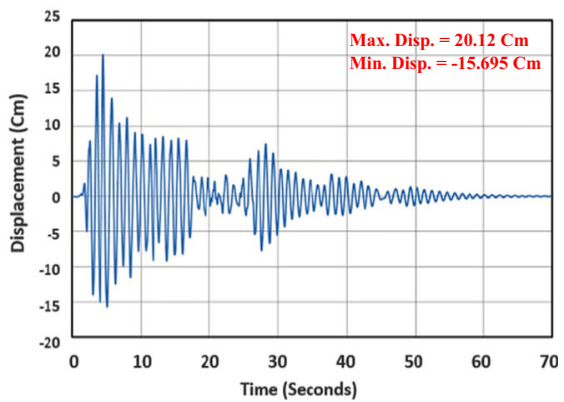

(d) Fix-based Model

El Centro earthquake (in Y-direction)

Fig. 25 (continued)

embedment effects, and kinematic pile response. In this section, foundation input motion (FIM) is calculated based on the proposed method in the NIST report (Stewart et al. 2012). In this regard, the following steps are followed:

- Fourier transform of free-field ground motion is calculated.

- Amplitude of Fourier transform is modified by consideration of base-slab averaging and embedment effects.

- Inverse of Fourier transform is performed to obtain foundation input motion.

Figure 19 depicts the acceleration records of the Hollis Center earthquake in the following three situations: free field, modified by base-slab averaging (BSA) 
consideration, and modified with both BSA embedment and embedment effect. As shown in Fig. 20, the Fourier transform of these cases is multiplied to consider kinematic interaction effects.

Dynamic soil stiffness parameters, i.e., stiffness and damping parts as well as effective foundation input for vertical, horizontal, and rocking degrees of freedom, are calculated using the FCONE program. Outcomes are depicted against the dimensionless frequency parameter, $a_{0}=w 2 r_{0} / c_{s}$ (Figs. 21, 22, 23).

The mentioned characterization and structure evaluation method is normally used for seismic analysis of infrastructures as it was also applied to Building 54 . The first three identified mode shapes obtained from the ETABS analysis are shown in Fig. 24, where it can be seen that the application of SSI could cause approximately $10 \%$ increase in the captured periods of the building. A comparison was also made between the results of modal analysis by Celebi et al. (2014) and these 3D numerical predictions captured by using ETABS and FCONE programs. Good agreements have been achieved in the comparison of modal analysis results.

In the following section, time-history analyses are conducted under previously considered ground motion records which were modified by consideration of kinematic interaction. In general, SSI tended to amplify the lateral deflections of the superstructures. Experienced roof displacements under excitation of considered ground motions with and without SSI effects are summarized in Table 6. Besides, the results of time-history analysis for all cases are displayed in more detail, as shown in Fig. 25. It can be seen that the displacements increased by consideration of the SSI effects.

To determine the sensitivity in the structure's response from an analytical perspective, we computed both minimum and maximum horizontal accelerations under excitation of considered ground motions with and without SSI effects, which is presented in Table 7.

Moreover, the horizontal roof acceleration response history of the building during the considered earthquakes is plotted in Fig. 26, for fixed-base conditions. It can be seen that the experienced roof accelerations are decreased by consideration of the SSI effect.

Figure 27 shows a schematic of the building depicting important dimensions as well as locations and orientations of the 36 accelerometers deployed throughout the building. Each accelerometer channel is connected via a cable to a 36-channel central recording system. The accelerometers are distributed as three per level to

Table 7 Minimum and maximum vertical accelerations under excitation of considered ground motions with and without SSI effects

\begin{tabular}{|c|c|c|c|c|c|c|c|c|}
\hline & \multicolumn{4}{|c|}{ Flexible-base model $\left(\mathrm{m} / \mathrm{s}^{2}\right)$} & \multicolumn{4}{|c|}{ Fixed-base model $\left(\mathrm{m} / \mathrm{s}^{2}\right)$} \\
\hline & Min. Y & Max. Y & Min. X & Max. X & Min. Y & Max. Y & Min. X & Max. X \\
\hline Hollis Center & -0.173 & 0.151 & -0.187 & 0.177 & -0.305 & 0.358 & -0.316 & 0.291 \\
\hline Hotel Azadi & -15.8 & 14.68 & -10.6 & 11.0 & -14.82 & 15.85 & -12.4 & 15.2 \\
\hline El Centro & -10.568 & 7.69 & -6.48 & 7.91 & -10.2 & 11.65 & -8.42 & 8.52 \\
\hline
\end{tabular}



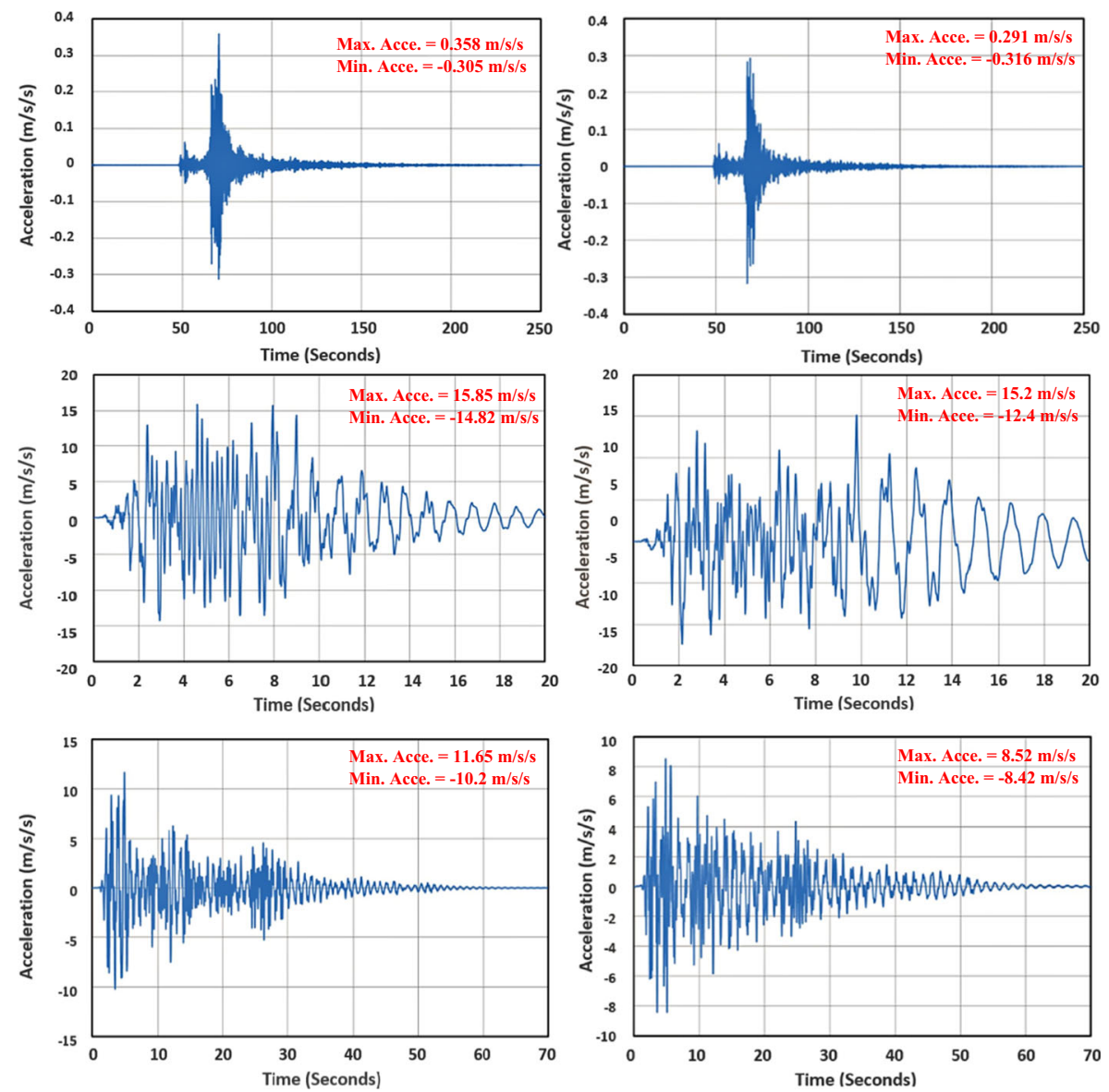

Fig. 26 The roof acceleration under excitation of three considered ground motions for fixed-base condition

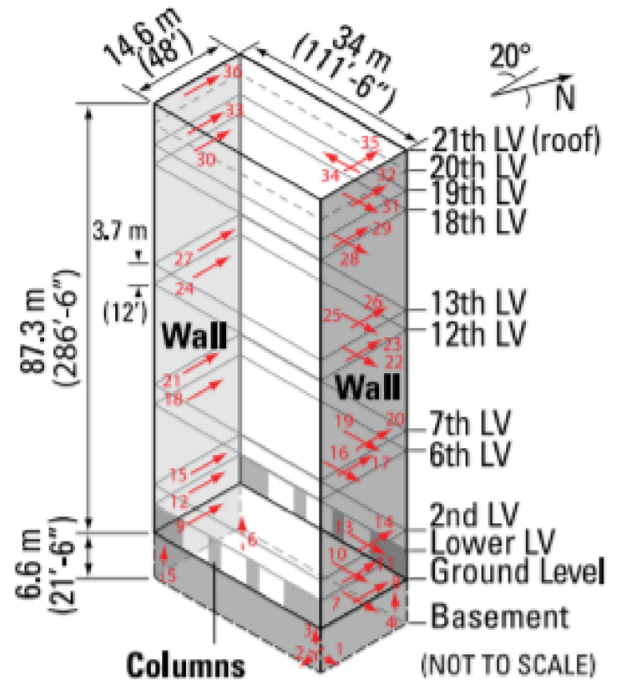

Fig. 27 Distribution of accelerometers in the MIT building no. 54 

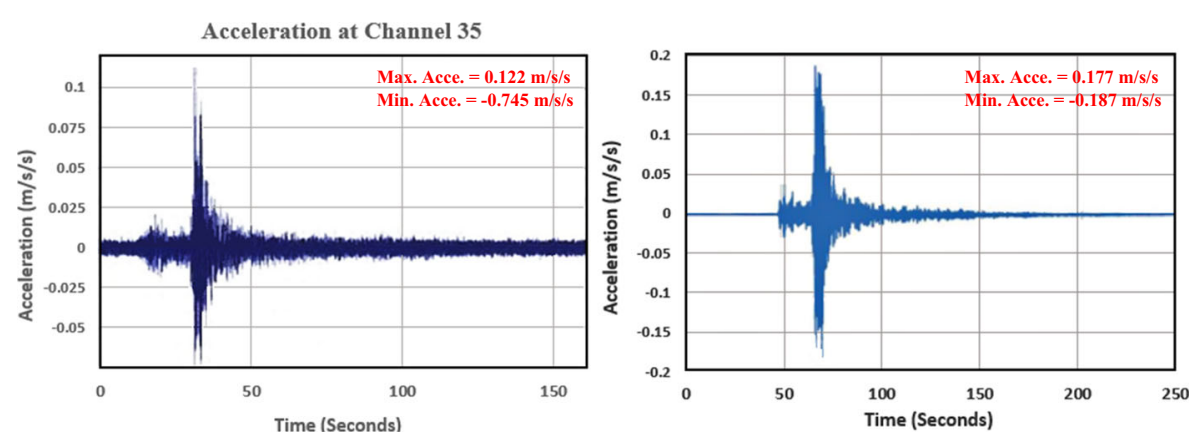

Fig. 28 Measured vs. calculated roof acceleration in X (or 1) direction under Boston ground motion excitation

capture the real acceleration values under the Hollis Center ground motion excitation in a building. The simulation and dynamic analysis of the building under seismic loads was compared to measured values. It can be seen from Fig. 28 that there is a good agreement between results of the roof acceleration in the X direction obtained from the FEM model (ETABS) and recorded values.

\section{Conclusion}

The present study investigates the effectiveness of applying the enhanced cone model to analyze the dynamic response of pile groups in two tall and massive building projects. For this purpose, we have developed a new computer program in which the seismic behavior of pile-soil-pile-structure interaction on a large building is investigated as a whole considering pile-group effect and soil constitutive model according to the cone theory. This program utilizes the equivalent dynamic modeling concept in the analysis of soil dynamics and pile-foundation interaction. The main conclusions drawn from the results are given as follows:

- The enhanced cone model allows the non-linearity of the near-field soil (plastic zone) to be represented by an equivalent linear manner, thereby reducing the degrees of freedom compared to the FEM method and consequently reducing computational effort. The results presented in this article are obtained from substructure approach in the frequency domain which is formulated on the basis of the cone method derived from the fundamental solution for a homogeneous, isotropic, and linear-elastic continuum. The presented model is also capable of incorporating the angular wave incidence from the far-field.

- By comparing the obtained results, it can be concluded that considering the effects of the SPSI can alter the dynamic characteristics of the structural system. It is shown that the effects of soil-structure interaction are demonstrated as increasing the period of vibrations and the lateral deflections as well as decreasing the experienced roof accelerations. Consequently, the in-story drifts of the structures were amplified in comparison with the fixed-base model. Therefore, ignoring the SPSI effects in such cases could affect the predicted damage level of structural and non-structural elements during an earthquake, resulting in considerable deviations. 
- Linear (frequency domain) SSI analysis can be employed for prediction of dynamic response of structures in low-to-moderate-intensity shaking earthquakes, such as these real cases that were located in a moderate-level seismic zone. Besides, the consequences might differ for extreme shaking that results in highly non-linear soil where the non-linear effects, including gapping, sliding, and uplift, are greatest in the immediate vicinity of the soil-structure boundary, and these cannot be captured using equivalent linear techniques.

- The capability of the cone method to predict the dynamic SPSI effects gives it an advantage over other time-consuming rigorous methods. This approach leads to physical insight with conceptual clarity, which is simple to use and solve, as the mathematical solution is simplified, and provides sufficient generality (layered site, embedment, all frequencies) and acceptable engineering accuracy. The accuracy of any analysis is limited anyway, because of the many uncertainties, some of which can never be eliminated (for instance, the definition of the dynamic loads and the values of the dynamic soil properties in the analysis of a structure). The analysis with cones fits the size and economics of practical engineering projects. Thus, the results presented in this article can contribute to relevant engineers in designing safe and economical structures based on foundation vibration and dynamic SPSI analysis in practical projects whenever possible.

Open Access This article is distributed under the terms of the Creative Commons Attribution 4.0 International License (http://creativecommons.org/licenses/by/4.0/), which permits unrestricted use, distribution, and reproduction in any medium, provided you give appropriate credit to the original author(s) and the source, provide a link to the Creative Commons license, and indicate if changes were made.

\section{References}

Bao, Y., Ye, G., Ye, B., Zhang, F.: Seismic evaluation of soil-foundation-superstructure system considering geometry and material nonlinearities of both soils and structures. Soils Found. 52(2), 257-278 (2012)

Baranov, V.A.: On the calculation of excited vibrations of an embedded foundation. In: Voprosy Dinamiki Prochnocti, vol. 14. Polytechnic Institute Riga, Riga, Latvia (1967)

Çelebi, M., Toksöz, N., Büyüköztürk, O.: Rocking behavior of an instrumented unique building on the MIT campus identified from ambient shaking data. Earthquake Spectra. 30(2), 705-720 (2014)

Chore, H.S., Ingle, R.K., Sawant, V.A.: Building frame-pile foundation-soil interaction analysis: a parametric study. Interaction and Multiscale Mechanics. 3(1), 55-79 (2010)

Craig, R.R.J., Kurdila, A.J.: Fundamentals of Structural Dynamics. Wiley, Hoboken (2006)

Dobry, R., Gazetas, G.: Simple method for dynamic stiffness and damping of floating pile groups. Geotechnique. 38(4), 557-574 (1988)

El Naggar, H., \& El Naggar, M. H.: Simplified approximate approach to group effect in pile dynamics. In Fourth International Conference on Earthquake Geotechnical Engineering, Greece, vol. 1325 (2007)

Fan, K., Gazetas, G., Kaynia, A., Kausel, E., Ahmad, S.: Kinematic seismic response of single piles and pile groups. J. Geotech. Eng. ASCE. 117(12), 1860-1879 (1991)

Ghandil, M., Behnamfar, F.: The near-field method for dynamic analysis of structures on soft soils including inelastic soil-structure interaction. Soil Dyn. Earthq. Eng. 75, 1-17 (2015)

Guin, J., Banerjee, P.K.: Coupled soil-pile-structure interaction analysis under seismic excitation. J. Struct. Eng. 4(434), 434444 (1998). https://doi.org/10.1061/(ASCE)0733-9445(1998)124

Haley, and Aldrich,: Isoseismal/Geological Conditions Maps for Eastern Massachusetts, Unpublished report to the Massachusetts Civil Defense Agency (now the Massachusetts Emergency Management Agency), Framingham, MA (1983). 
Han, Y.: Seismic response of tall building considering soil-pile-structure interaction. Earthq. Eng. Eng. Vib. 1(1), 57-65 (2002)

Ismail, S., Kaddah, F., Raphael, W.: Seismic soil structure interaction of a midrise frame structure. In: International congress and exhibition" Sustainable Civil Infrastructures: Innovative Infrastructure Geotechnology", pp. 73-88. Springer, Cham (2018, November)

Jaya, K.P., Prasad, A.M.: Dynamic behaviour of pile foundations in layered soil medium using cone frustums. Géotechnique. 54(6), 399-414 (2004)

Jen, L.: Personal communication (2011).

Jennings, P., Kuroiwa, J.: Vibration and soil-structure interaction tests of a nine-story reinforced concrete building. Bull. Seismol. Soc. Am. 58, 891-916 (1968)

Kaynia, A. M.: Dynamic Stiffness and Seismic Response of Pile Groups (Doctoral dissertation, Massachusetts Institute of Technology) (1982)

Kaynia, A.M., Kausel, E.: Dynamics of piles and pile groups in layered soil media. Soil Dyn. Earthq. Eng. 10(8), 386-401 (1991)

Massumi, A., Tabatabaiefar, H.R.: Effects of Soil-Structure Interaction on Seismic Behavior of Reinforced Concrete Buildings with Moment Resisting System (Using Direct Method). International Institute of Earthquake Engineering and Seismology (IIEES), Tehran, Iran (2007)

Meek, J.W., Wolf, J.P.: Insights on cutoff frequency for foundation on soil layer. Earthq. Eng. Struct. Dyn. 20, 651-665 (1991) Also in Proceedings of the 9th European Conference on Earthquake Engineering, EAEE, Moscow 1990, 4-A, 34-43

Meek, J.W., Wolf, J.P.: Cone models for an embedded foundation. J. Geotech. Eng. 120, 60-80 (1994)

Novak, M.: Discussion of dynamic response of arbitrarily shaped foundations: experimental verification. J. Geotech. Eng. 113(11), 1410-1412 (1987)

Novak, M., Nogami, T.: Soil-pile interaction in horizontal vibration. International Journal of Earthquake Engineering and Structural Dynamics. 5, 263-281.19 (1977)

Pal, A.S., Baidya, D.K.: Dynamic analysis of pile foundation embedded in homogeneous soil using cone model. J. Geotech. Geoenviron. 144(8), 06018007 (2018)

Pitilakis, D., Dietz, M., Wood, D.M., Clouteau, D., Modaressi, A.: Numerical simulation of dynamic soilstructure interaction in shaking table testing. Soil Dyn. Earthq. Eng. 28, 453-467 (2008)

Sadeghi Hokmabadi, A., Fatahi, B., Far, H., \& Samali, B.: Effects of soil-pile-structure interaction on seismic response of moment resisting buildings on soft soil. In 3rd International Conference on New Developments in Soil Mechanics and Geotechnical Engineering. Near East University Press, Turkey (2012)

Stacul, S., Squeglia, N.: Analysis method for laterally loaded pile groups using an advanced modeling of reinforced concrete sections. Materials. 11(2), 300 (2018)

Stewart, J., Fenves, G., Seed, R.: Seismic soil-structure interaction in buildings. I: analytical methods. J. Geotech. Geoenviron. Eng. 125, 26-37 (1999a)

Stewart, J., Seed, R., Fenves, G.: Seismic soil-structure interaction in buildings. II: empirical findings. J. Geotech. Geoenviron. Eng. 125, 38-48 (1999b)

Stewart, J., Crouse, C. B., Hutchinson, T. C., Lizundia, B., Naeim, F., \& Ostadan, F.: Soil-Structure Interaction for Building Structures (No. Grant/Contract Reports (NISTGCR)-12-917-21) (2012)

Trocha, P. A.: Characterization of Structural Properties and Dynamic Behavior Using Distributed Accelerometer Networks and Numerical Modeling (Doctoral dissertation, Massachusetts Institute of Technology) (2013)

Ülker-Kaustell, M., Karoumi, R., Pacoste, C.: Simplified analysis of the dynamic soil-structure interaction of a portal frame railway bridge. Eng. Struct. 32(11), 3692-3698 (2010)

Wolf, J.P.: Dynamic Soil-Structure Interaction. Prentice-Hall, Englewood Cliffs (1985)

Wolf, J.P.: Foundation Vibration Analysis Using Simple Physical Models. Prentice Hall (1994) ISBN: 9780132442695

Wolf, J.P., Deeks, A.J.: Foundation Vibration Analysis: a Strength of Materials Approach. ButterworthHeinemann (2004)

Publisher's Note Springer Nature remains neutral with regard to jurisdictional claims in published maps and institutional affiliations. 


\section{Affiliations}

Sassan Mohasseb ${ }^{1} \cdot$ Niloufar Ghazanfari $^{1} \cdot$ Mohsen Rostami $^{1} \cdot$ Setayesh Rostami ${ }^{1}$

$\triangle$ Niloufar Ghazanfari

smteam.gmbh@gmail.com

1 Department of Civil Engineering, Smteam GmbH, Zurich, Switzerland 